\title{
Adolescent suicide and suicidal behavior
}

\author{
Jeffrey A. Bridge, Tina R. Goldstein, and David A. Brent \\ Western Psychiatric Institute and Clinic, University of Pittsburgh Medical Center, Pittsburgh, PA, USA
}

\begin{abstract}
This review examines the descriptive epidemiology, and risk and protective factors for youth suicide and suicidal behavior. A model of youth suicidal behavior is articulated, whereby suicidal behavior ensues as a result of an interaction of socio-cultural, developmental, psychiatric, psychological, and familyenvironmental factors. On the basis of this review, clinical and public health approaches to the reduction in youth suicide and recommendations for further research will be discussed. Keywords: Suicide, children, adolescents, suicidal behavior, risk factors.
\end{abstract}

During the past quarter-century, suicide among the young has emerged as a significant global public health problem. In many countries, youth suicide is one of the leading causes of death, having increased markedly from the 1960s through the early 1990s (Gould, Greenberg, Velting, \& Shaffer, 2003; World Health Organization, 2002).

Progress has been made in our understanding of the phenomenology and risk factors of adolescent suicide and suicidal behavior (Beautrais, 2000b; Evans, Hawton, \& Rodham, 2004; Gould et al., 2003; Pelkonen \& Marttunen, 2003; Shaffer \& Pfeffer, 2001). This report will first review the descriptive epidemiology of youth suicide and suicidal behavior. Then we examine risk for adolescent suicide and suicidal behavior with regard to salient domains: (1) mental and physical disorder; (2) personality and psychological traits; (3) family factors; (4) biology; (5) contagion; (6) access to lethal agents; and (7) intervention and clinical management. Finally, public health approaches to the reduction in youth suicide and further research will be discussed.

\section{Terminology}

In this review, definitions of suicidal thoughts and behavior developed by O'Carroll et al. (1996) and adopted by the Institute of Medicine (2002) will be used (Goldsmith, Pellmar, Kleinman, \& Bunney, 2002). Suicidal ideation refers to thoughts of harming or killing oneself. Attempted suicide is a non-fatal, self-inflicted destructive act with explicit or inferred intent to die. Suicide is a fatal self-inflicted destructive act with explicit or inferred intent to die. Suicidality refers to all suicide-related behaviors and thoughts including completing or attempting suicide, suicidal ideation or communications. This review will focus on the spectrum of suicidality, from suicidal ideation to suicidal behavior, with passive thoughts of death and completed suicide representing extreme ends of the risk spectrum (Brent et al., 1988; Gould et al., 1998; Lewinsohn, Rohde, \& Seeley, 1996; Reinherz et al., 1995). Non-suicidal self-harm, sometimes referred to as 'parasuicide,' is viewed as distinct from suicidal behavior and most commonly involves self-cutting without suicidal intent (Simpson, 1975). Factors associated with parasuicide will not be reviewed, although often, non-suicidal self-harm and suicidal behavior co-occur (for a recent review of parasuicide, see Welch, 2001).

\section{Descriptive epidemiology of youth suicide and suicidal behavior}

\section{Suicidal ideation}

The point prevalence of suicidal ideation in adolescence is approximately $15-25 \%$, ranging in severity from thoughts of death and passive ideation to specific suicidal ideation with intent or plan (Grunbaum et al., 2004). The latter is much less frequent, with annual incidence rates of $6.0 \%$ and $2.3 \%$ in adolescent girls and boys, respectively (Lewinsohn et al., 1996).

\section{Suicide attempt}

Lifetime estimates of suicide attempts among adolescents range from $1.3-3.8 \%$ in males and $1.5-$ $10.1 \%$ in females, with higher rates in females than males in the older adolescent age range (Andrews \& Lewinsohn, 1992; Fergusson \& Lynskey, 1995b; Lewinsohn et al., 1996). Annual suicide attempt rates among adolescents requiring medical attention are on the order of 1-3\% (Grunbaum et al., 2004). However, the actual number of suicide attempts may be underestimated because many youth attempters will not seek treatment or will not be accurately documented (Hawton \& Goldacre, 1982b; Lewinsohn, Rohde, \& Seeley, 1994).

\section{Repetition of suicidal behavior}

Suicidal behavior tends to be recurrent, and may be a harbinger of suicide completion. Estimates of the risk of repetition of suicidal behavior range from $10 \%$ 
upon a 6-month follow-up to $42 \%$ upon 21 -month follow-up, with a median recurrence rate of $5-15 \%$ per year (Goldston et al., 1999; Hawton \& Catalan, 1987; Hawton, Zahl, \& Weatherall, 2003). The rates of subsequent completed suicide among attempters are $0.5-1.0 \%$ per year, which are substantially elevated compared to the general population (Hawton et al., 2003; Otto, 1972).

\section{Completed suicide}

Table 1 gives the most recent youth suicide statistics from selected countries reporting mortality data to the World Health Organization (2002). Suicide rates in the Russian Federation and former Soviet states are especially high, along with New Zealand, Finland, and Ireland. These countries have rates of suicide two to three times higher than the United States, which is in the middle of the rates for the various countries selected.

\section{Age and pubertal status}

Suicide rates consistently increase from childhood to adolescence, perhaps because of the greater preval-

Table 1 Youth suicide rates in selected countries by age and $\operatorname{sex}^{a}$

\begin{tabular}{|c|c|c|c|c|c|c|c|}
\hline \multirow[b]{2}{*}{ Country } & \multirow[b]{2}{*}{ Year } & \multicolumn{3}{|c|}{ 5-14 years } & \multicolumn{3}{|c|}{ 15-24 years } \\
\hline & & M & $\mathrm{F}$ & All & M & $\mathrm{F}$ & All \\
\hline Lithuania & 2002 & 1.6 & 0.4 & 1.1 & 59.4 & 5.9 & 33.1 \\
\hline Russia & 2002 & 3.8 & 1.0 & 2.4 & 56.9 & 9.2 & 33.4 \\
\hline New Zealand & 2000 & 1.0 & 0.3 & 0.7 & 30.4 & 5.7 & 18.2 \\
\hline Latvia & 2002 & 2.7 & 0.0 & 1.4 & 29.8 & 4.1 & 17.2 \\
\hline Ireland & 2000 & 0.3 & 0.0 & 0.2 & 25.3 & 6.5 & 16.1 \\
\hline Norway & 2001 & 0.0 & 0.0 & 0.0 & 22.1 & 7.6 & 15.0 \\
\hline Australia & 2001 & 0.3 & 0.3 & 0.3 & 20.7 & 4.8 & 12.9 \\
\hline Canada & 2000 & 1.4 & 0.9 & 1.1 & 20.2 & 5.5 & 13.0 \\
\hline Austria & 2002 & 0.4 & 0.4 & 0.4 & 20.1 & 3.6 & 12.0 \\
\hline Poland & 2001 & 1.3 & 0.1 & 0.7 & 19.3 & 2.4 & 11.0 \\
\hline Switzerland & 2000 & 0.9 & 0.2 & 0.6 & 18.5 & 4.9 & 11.8 \\
\hline Czech Republic & 2001 & 0.7 & 0.3 & 0.5 & 17.2 & 2.6 & 10.1 \\
\hline Hungary & 2002 & 0.7 & 0.5 & 0.6 & 17.0 & 3.6 & 10.5 \\
\hline United States & 2000 & 1.2 & 0.3 & 0.7 & 17.0 & 3.0 & 10.2 \\
\hline Japan & 2000 & 0.9 & 0.3 & 0.6 & 15.8 & 6.9 & 11.5 \\
\hline Germany & 2001 & 0.8 & 0.3 & 0.5 & 12.4 & 2.7 & 7.7 \\
\hline France & 1999 & 0.5 & 0.2 & 0.4 & 12.3 & 3.4 & 7.9 \\
\hline Israel & 1999 & 1.0 & 0.0 & 0.5 & 11.4 & 1.3 & 6.5 \\
\hline Sweden & 2001 & 0.3 & 0.5 & 0.4 & 11.2 & 3.6 & 7.5 \\
\hline United Kingdom & 1999 & 0.1 & 0.0 & 0.1 & 10.6 & 2.5 & 6.7 \\
\hline Singapore & 2001 & 1.2 & 0.8 & 1.0 & 9.7 & 7.6 & 8.7 \\
\hline Netherlands & 2000 & 0.5 & 0.0 & 0.3 & 9.4 & 1.9 & 5.7 \\
\hline $\begin{array}{l}\text { China } \\
\text { (Hong Kong SAR) }\end{array}$ & 1999 & 0.5 & 0.5 & 0.5 & 9.0 & 6.8 & 7.9 \\
\hline Argentina & 1996 & 0.4 & 0.3 & 0.3 & 8.8 & 3.4 & 6.1 \\
\hline Spain & 2000 & 0.3 & 0.2 & 0.2 & 7.7 & 1.5 & 4.7 \\
\hline Mexico & 1995 & 0.5 & 0.3 & 0.4 & 7.6 & 2.0 & 4.7 \\
\hline Italy & 2000 & 0.3 & 0.1 & 0.2 & 6.7 & 1.6 & 4.2 \\
\hline $\begin{array}{l}\text { China (mainland, } \\
\text { selected areas) }\end{array}$ & 1999 & 0.9 & 0.8 & 0.8 & 5.4 & 8.6 & 6.9 \\
\hline Portugal & 2000 & 0.0 & 0.0 & 0.0 & 3.7 & 1.0 & 2.4 \\
\hline
\end{tabular}

${ }^{a}$ Rank-ordered by 15-24 male suicide rates.

Source of data: World Health Organization (2002) ence of psychopathology in adolescents, particular combinations of mood disorder and substance abuse, and the greater risk for suicide conveyed by psychopathology in older adolescents (Brent, Baugher, Bridge, Chen, \& Chiappetta, 1999; Groholt, Ekeberg, Wichstrom, \& Haldorsen, 1998; Shaffer et al., 1996). Adolescents are also more cognitively capable of planning and executing a lethal suicide attempt, and show greater planning and intent than younger suicide victims (Brent et al., 1999; Groholt et al., 1998). For the same reason, cognitively precocious youths are overrepresented in younger suicide victims (Shaffer, 1974). Moreover, older adolescents receive more autonomy and less supervision and social support from parents, which may increase the opportunity for disconnection and make recognition of imminent risk less likely.

\section{Gender}

Rates of completed suicide for young females are lower than those for males in all countries for which data are systematically collected, with the exception being China (Table 1). This is in contrast with suicidal ideation and suicide attempts, where females have much higher rates than males after puberty (Fergusson, Woodward, \& Horwood, 2000; Grunbaum et al., 2004). The gender difference in youth suicide is most likely due to the greater likelihood of males having multiple risk factors such as comorbid mood and alcohol abuse disorders, greater levels of aggression, and choice of more lethal suicide attempt methods, which make them more likely than females to make a lethal suicide attempt (Brent et al., 1999; Gould, Fisher, Parides, Flory, \& Shaffer, 1996; Shaffer et al., 1996; Shaffer \& Pfeffer, 2001). In countries such as China more females complete suicide than males, especially in rural areas where highly lethal insecticides are common and treatment facilities harder to access (World Health Organization, 2002).

\section{Race and ethnicity}

Rapid cultural transition may contribute to increases in youth suicide rates. Assimilation and loss of traditional cultural practices can increase alienation, intra-generational conflict, and create a situation in which an individual does not feel strongly affiliated with either the traditional or the alternative culture. For example, the increase in suicide in Chinese women may be related to family disruption and marginalization of women as a consequence of transition from a traditional agrarian to a modern urban capitalist society (Ji, Kleinman, \& Becker, 2001; M. R. Phillips, Liu, \& Zhang, 1999).

In the United States, rates of attempted and completed suicide are especially high among Native Americans (Anderson, 2002; Borowsky, Resnick, Ireland, \& Blum, 1999; Wallace, Calhoun, Powell, O’Neil, \& James, 1996), a pattern observed among 
indigenous peoples worldwide (Beautrais, 2001a; Boothroyd, Kirmayer, Spreng, Malus, \& Hodgins, 2001; C. Cantor \& Neulinger, 2000). Berlin (1987) found that those tribes with the highest suicide rates had higher rates of alcoholism, incarceration, unemployment, and lack of retention of traditional Native American culture.

Whites traditionally have had higher suicide rates than non-whites in the United States, but the gap has been narrowing due to an increase in youth suicide among African American males (Centers for Disease Control and Prevention, 2005; Joe and Kaplan, 2002; Shaffer, Gould, \& Hicks, 1994). Assimilation and loss of traditional protective factors may also partially explain the class gradient in suicide among young African Americans, with risk increasing with higher social class (Gould et al., 1996). Although Hispanic youth in the USA are not disproportionately represented among suicide completers (Demetriades et al., 1998), they show higher rates of suicidal ideation and attempted suicide (Grunbaum et al., 2004).

\section{Secular trends}

During the past decade, there has been a significant decline in youth suicide in several countries (Table 2). Possible explanations for the recent decline in the USA and Australia may relate to more restrictive gun laws (Webster, Vernick, Zeoli, \& Manganello, 2004). Pharmacoepidemiology studies have shown a relationship between the degree of increases in SSRI prescriptions and sales and the decline in youth suicide (Ludwig \& Marcotte, 2005; Olfson, Shaffer, Marcus, \& Greenberg, 2003), with a dose-response relationship between the degree increase in selective serotonin reuptake inhibitors (SSRIs) sales or prescriptions, and the extent of decline in the suicide rate.

\section{Methods of suicide}

The three leading methods of suicide among youth in the United States are firearms, hanging, and poisoning, respectively, whereas in most other Western countries hanging and vehicular exhaust predominate, followed by firearms and poisoning (Beautrais, 2000a; C. Cantor \& Neulinger, 2000; Centers for Disease Control and Prevention, 2005). With limitations on availability of firearms, the United States and Australia have seen a decline in the use of firearms, partially offset by substitution of other methods such as hanging and vehicular exhaust (Beautrais, 2000a; Bridge, Barbe, \& Brent, 2005; Centers for Disease Control and Prevention, 2004). Suicide by jumping is a relatively uncommon method of suicide in most countries (Gunnell \& Nowers, 1997b), although jumping from a height is the primary method of choice for suicide completers in Hong Kong (Hau, 1993).
Table 2 Youth suicide rates in selected countries by age and year

\begin{tabular}{|c|c|c|c|c|}
\hline \multirow[b]{2}{*}{ Country } & \multicolumn{2}{|c|}{$5-14$ years } & \multicolumn{2}{|c|}{$15-24$ years } \\
\hline & 1990 & 2000 & 1990 & 2000 \\
\hline \multicolumn{5}{|c|}{ Eastern Europe/former Soviet Union } \\
\hline Estonia & 1.3 & .5 & 17.2 & 18.1 \\
\hline Russia & 1.4 & 2.7 & 17.8 & 33.7 \\
\hline Latvia & 1.9 & 1.9 & 13.6 & 17.9 \\
\hline Hungary & 1.7 & .9 & 14.3 & 10.7 \\
\hline Poland & .6 & .9 & 9.6 & 11.4 \\
\hline Czech Republic & .4 & 1.0 & 8.7 & 10.5 \\
\hline \multicolumn{5}{|l|}{ Northern Europe } \\
\hline Finland & .6 & .3 & 31.3 & 19.9 \\
\hline Norway & .8 & .7 & 14.4 & 15.5 \\
\hline Sweden & .5 & .2 & 10.1 & 8.7 \\
\hline Germany & .4 & .4 & 9.5 & 7.7 \\
\hline Netherlands & .4 & .3 & 5.9 & 5.7 \\
\hline \multicolumn{5}{|l|}{ English-speaking } \\
\hline New Zealand & .4 & .7 & 23.1 & 18.2 \\
\hline Australia & .2 & .3 & 15.9 & 13.3 \\
\hline Canada & .8 & 1.1 & 15.0 & 13.0 \\
\hline United States & .8 & .8 & 13.2 & 10.2 \\
\hline Ireland & .6 & .2 & 9.3 & 16.1 \\
\hline United Kingdom & .03 & .1 & 7.2 & 6.8 \\
\hline \multicolumn{5}{|l|}{ Catholic Europe } \\
\hline Austria & .3 & .9 & 15.4 & 13.9 \\
\hline France & .3 & .6 & 9.3 & 7.9 \\
\hline Spain & .4 & .2 & 4.5 & 4.7 \\
\hline Portugal & .3 & .0 & 5.4 & 2.4 \\
\hline Italy & .3 & .2 & 4.0 & 4.2 \\
\hline \multicolumn{5}{|l|}{ Asian } \\
\hline Singapore & .7 & 1.2 & 10.4 & 7.1 \\
\hline Japan & .3 & .6 & 7.0 & 11.5 \\
\hline Hong Kong & .2 & 1.4 & 7.1 & 6.5 \\
\hline \multicolumn{5}{|l|}{ Latin American } \\
\hline Argentina & .6 & .6 & 5.1 & 8.7 \\
\hline Mexico & .2 & .5 & 3.1 & 5.4 \\
\hline Other & & & & \\
\hline Israel & .2 & $.5^{\mathrm{a}}$ & 5.0 & $6.5^{\mathrm{a}}$ \\
\hline
\end{tabular}

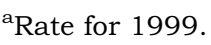

Based on country groupings of Kelleher and Chambers (2003). Source of data: World Health Organization (2002).

\section{Risk factors for completed and attempted suicide}

\section{Suicide ideation}

Longitudinal studies have shown that the more severe (high intent or planning) and pervasive (high frequency or duration) the suicidal ideation, the more likely such ideation is to eventuate in an attempt (Lewinsohn et al., 1996). Attempters who show persistent suicidal ideation, particularly with a plan or high intent to commit suicide or both, are at increased risk to reattempt (Goldston et al., 1999; Lewinsohn et al., 1996).

\section{Previous suicidal behavior}

A prior suicide attempt is the single most potent risk factor for youth suicide in both case-control and prospective studies, elevating the risk of a subsequent completion 10-60 fold (Brent et al., 1999; 
Kotila \& Lonnqvist, 1989; Marttunen, Aro, \& Lonnqvist, 1992; Shaffer et al., 1996). The risk for repetition is highest in the first 3 to 6 months after a suicide attempt, but remains substantially elevated from the general population for at least 2 years (Goldston et al., 1999; Lewinsohn et al., 1996).

\section{Lethality of the suicide attempt}

Suicide attempters who make attempts of high medical lethality (e.g., hanging, shooting, or jumping) are at extremely high risk for completed suicide (Brent et al., 1988; Garfinkel, Froese, \& Hood, 1982; Otto, 1972). However, an attempt of low lethality does not necessarily indicate low suicidal intent, especially in younger children whose cognitive immaturity makes it difficult to formulate and execute a suicidal plan. In an impulsive individual for whom a lethal agent such as a firearm or paracetamol is available, an attempt with relatively low intent may result in a medically serious and even fatal attempt (Brent et al., 1993f; Gunnell et al., 1997a).

\section{Intent and motivation}

Suicidal intent, or the extent to which the suicide attempter wishes to die, is a powerful discriminative and predictive variable for repetition of suicide attempts and completed suicide (Beck, Morris, \& Beck, 1974; Brent et al., 1988; Hawton \& Goldacre, $1982 b)$. Suicidal intent consists of four orthogonal factors: (1) belief about intent; (2) preparation before attempt; (3) prevention of discovery; and (4) communication (Brent et al., 1988; Kingsbury, 1993). Items that discriminate between completers and attempters include evidence of planning, timing the attempt to avoid detection, confiding suicidal plans ahead of time, and expressing a wish to die (Brent et al., 1988).

Motivation is the reason given by the patient and family for the suicidal act. For the one-third of attempters with the highest suicidal intent, their motivation is to die or to permanently escape a psychologically painful situation (Hawton \& Catalan, 1987; Kienhorst, De Wilde, Diekstra, \& Wolters, 1995). Those attempters who wish to die, to escape a painful situation (e.g., an abusive home), or expect to reattempt are at high risk for recurrent suicide attempts (Cohen-Sandler, Berman, \& King, 1982; Goldston et al., 2001). Often, motivations for engaging in suicidal behavior reflect difficulties with social skills and interpersonal effectiveness (Hawton \& Catalan, 1987; Kienhorst et al., 1995).

\section{Precipitant}

The most common precipitants for adolescent suicidal behavior are interpersonal conflict or loss, particularly for youth with substance abuse (Brent et al., 1999, 1993e; Gould et al., 1996). Discord is a risk factor for completed and attempted suicide (Beautrais, 2000b). The more unrelenting the discord, the more likely a suicide attempter is to repeat (Asarnow \& Carlson, 1988). In youth with conduct disorder and substance abuse, legal and disciplinary problems are common precipitants for suicidal behavior and suicide, reflecting in part contributions that impulsivity, aggression, and substance use make to suicidal risk (Brent et al., 1999, 1993e; Marttunen, Aro, Henriksson, \& Lonnqvist, 1994b).

\section{Mental disorder}

Any psychiatric disorder. Psychiatric disorder is present in nearly $90 \%$ of unselected adolescent suicide victims, and poses a 9-fold increased risk for suicide (Brent et al., 1988, 1993; Marttunen, Aro, Henriksson, \& Lonnqvist, 1991; Shaffer et al., 1996; Shafii, Carrigan, Whittinghill, \& Derrick, 1985; Shafii, Steltz-Lenarsky, Derrick, Beckner, \& Whittinghill, 1988) (see Tables 3 and 4).

Similarly, in approximately $80 \%$ of community and referred cases of suicide attempts, there are associated psychopathological conditions (Andrews \& Lewinsohn, 1992; Beautrais, Joyce, \& Mulder, 1998a; Fergusson \& Lynskey, 1995b; Gould et al., 1998; Kerfoot, Dyer, Harrington, Woodham, \& Harrington, 1996; Reinherz et al., 1995). Moreover, chronicity and severity of disorder have been associated with increased suicidal risk (Brent et al., 1993b; Ryan et al., 1987).

Mood disorders. Mood disorders contribute substantially to risk of completed and attempted suicide in both genders (Beautrais et al., 1998a; Fergusson \& Lynskey, 1995a; Garrison, Jackson, Addy, McKeown, \& Waller, 1991; Gould et al., 1998; Joffe, Offord, \& Boyle, 1988; Lewinsohn et al., 1994; Reinherz et al., 1995) (Tables 3 and 4). Bipolar disorder, especially in a mixed state, was a risk factor for completed suicide in some studies (Brent et al., 1988, 1993) but not others (Marttunen et al., 1991; Shaffer et al., 1996). Bipolar disorder, including bipolar II and bipolar NOS, greatly increased the risk of attempts in epidemiologic and clinical samples (Goldstein et al., in press; Lewinsohn, Klein, $\&$ Seeley, 1995).

Longitudinal studies also support associations between mood disorders and attempted and completed suicide (Weissman et al., 1999). In one prospective case-control study of adult subjects who had adolescent-onset MDD $(n=73)$ and controls with no evidence of past or current psychiatric disorder $(n=37)$, the 10 -plus year mortality due to suicide of adults with adolescent-onset MDD was $7.7 \%$ versus $0 \%$ in controls, with a 5 -fold increased risk of first suicide attempt (Weissman et al., 1999).

Substance use disorders. Substance abuse (alcohol/drug abuse) plays a significant role in youth 
Table 3 Psychiatric disorder in young suicide victims (\%)

\begin{tabular}{|c|c|c|c|c|c|c|c|}
\hline & $\begin{array}{l}\text { Shafii } \\
(1988)\end{array}$ & $\begin{array}{c}\text { Brent } \\
(1988)\end{array}$ & $\begin{array}{l}\text { Marttunen } \\
\quad(1991)\end{array}$ & $\begin{array}{c}\text { Brent } \\
(1993)\end{array}$ & $\begin{array}{l}\text { Apter } \\
(1993)\end{array}$ & $\begin{array}{l}\text { Shaffer } \\
\text { (1996) }\end{array}$ & $\begin{array}{c}\text { Houston } \\
(2001)\end{array}$ \\
\hline Age range & $11-19$ & $13-19$ & $13-19$ & $13-19$ & $18-21$ & $\leq 20$ & $15-24$ \\
\hline No. of suicide completers & $N=21$ & $N=27$ & $N=53$ & $N=67$ & $N=43$ & $N=119$ & $N=27$ \\
\hline Any psychiatric disorder & 95 & 93 & 94 & 90 & 81 & 91 & 70 \\
\hline Any mood disorder & 76 & 63 & - & 49 & - & 61 & 44 \\
\hline Major depressive disorder & 38 & 41 & 23 & 43 & 54 & 32 & 15 \\
\hline Depressive disorder NOS & - & - & 25 & - & - & 3 & 7 \\
\hline Dysthymia & 10 & 22 & 4 & - & 5 & 13 & - \\
\hline Bipolar spectrum disorder & - & 22 & - & 18 & - & 2 & - \\
\hline Adjustment disorder & - & - & 21 & - & 7 & $5-6$ & - \\
\hline Any substance abuse & 62 & 41 & - & 27 & 0 & 35 & 7 \\
\hline Alcohol abuse & - & 37 & $26^{\mathrm{a}}$ & 24 & 0 & 22 & - \\
\hline Drug abuse & - & 30 & 4 & 13 & 0 & 25 & - \\
\hline Any anxiety disorder & - & 15 & 4 & 12 & 7 & 27 & 0 \\
\hline PTSD & - & - & - & - & - & - & - \\
\hline Panic disorder & - & 0 & - & - & - & - & - \\
\hline Disruptive disorder & - & - & - & - & - & 50 & - \\
\hline Conduct disorder & - & 22 & 8 & 28 & - & 46 & - \\
\hline Attention deficit disorder & - & 26 & 4 & 13 & - & 8 & - \\
\hline Eating disorder & - & - & - & - & - & 4 & 0 \\
\hline Schizophrenia & - & - & 6 & 0 & 7 & 3 & 11 \\
\hline Any Axis I Comorbidity & 81 & - & 43 & - & - & 70 & - \\
\hline Comorbidity on Axis I and/or II & - & - & 51 & - & - & - & 26 \\
\hline $\begin{array}{l}\text { Comorbidity of mood and } \\
\text { non-mood axis I disorders }\end{array}$ & $43^{b}$ & 44 & - & 23 & - & $5-13^{\mathrm{c}}$ & - \\
\hline No psychiatric diagnosis & 5 & 7 & 6 & 10 & 19 & 9 & 30 \\
\hline
\end{tabular}

${ }^{\mathrm{a}}$ Alcohol abuse or dependence; ${ }^{\mathrm{b}}$ mood disorder and substance abuse; ${ }^{\mathrm{c}}$ lifetime rate.

suicide, especially in older adolescent males when comorbid with mood disorder or disruptive disorders (Allebeck \& Allgulander, 1990; Brent et al., 1999; Renaud, Brent, Birmaher, Chiappetta, \& Bridge, 1999; Shaffer et al., 1996; Shafii et al., 1988) (Tables 3 and 4). While most studies in the USA show substance abuse to be a major risk factor primarily in male suicide, Marttunen and colleagues (1991), in a Finnish study, found similar rates in males and females.

Substance abuse is also a risk factor for attempted suicide, mainly in older samples (Andrews \& Lewinsohn, 1992; Beautrais et al., 1998a; Borowsky, Ireland, \& Resnick, 2001; Fergusson \& Lynskey, 1995a; Gould et al., 1998; Reinherz et al., 1995). Moreover, suicide attempters are more likely to have substance abuse/dependence disorders than suicidal ideators (Gould et al., 1998), suggesting that substance use may facilitate the transition from ideation to behavior.

Conduct disorder/Antisocial behavior. Disruptive disorders carry a 3-6 fold greater risk for youth suicide in case-control and longitudinal studies (Table 4), and are more likely to result in suicide in the presence of a current substance abuse disorder (Allebeck \& Allgulander, 1990; Brent et al., 1993; de Chateau, 1990; Groholt et al., 1998; Kuperman, Black, \& Burns, 1988; Renaud et al., 1999; Shaffer et al., 1996), and increase the risk for suicidal behavior as well (Andrews \& Lewinsohn, 1992; Beautrais et al., 1998a; Fergusson \& Lynskey, 1995b; Garrison, McKeown, Valois, \& Vincent, 1993; Joffe et al., 1988; Reinherz et al., 1995).

Anxiety disorder. Anxiety disorders are associated with youth suicide and attempted suicide, although in some studies its contribution to suicidal risk is attenuated after controlling for mood disorder and other conditions (Shaffer et al., 1996). However, panic attacks may increase the risk for suicidal behavior, even after controlling for mood and other disorders (Gould et al., 1998; Pilowsky, Wu, \& Anthony, 1999).

Post-traumatic stress disorder (PTSD). No psychological autopsy study of young suicide victims to date has reported rates of PTSD (Table 3). A school-based study found that PTSD symptomatology increased the risk of current suicidal ideation and past suicide attempt, even after controlling for depression and gender (Mazza, 2000). In one longitudinal study of suicidal ideation and attempts, early onset ( $\leq$ age 14) PTSD was associated with lifetime suicide attempt, but no concurrent association was found (Reinherz et al., 1995). In adults, the association between PTSD and suicidal behavior in patients with a lifetime history of MDD appears to be mediated by the frequency of cluster B personality disorder comorbidity (Oquendo et al., 2005).

Psychosis. Psychotic individuals are at increased risk for both suicide and attempted suicide, but suicide does not occur frequently in psychotic 


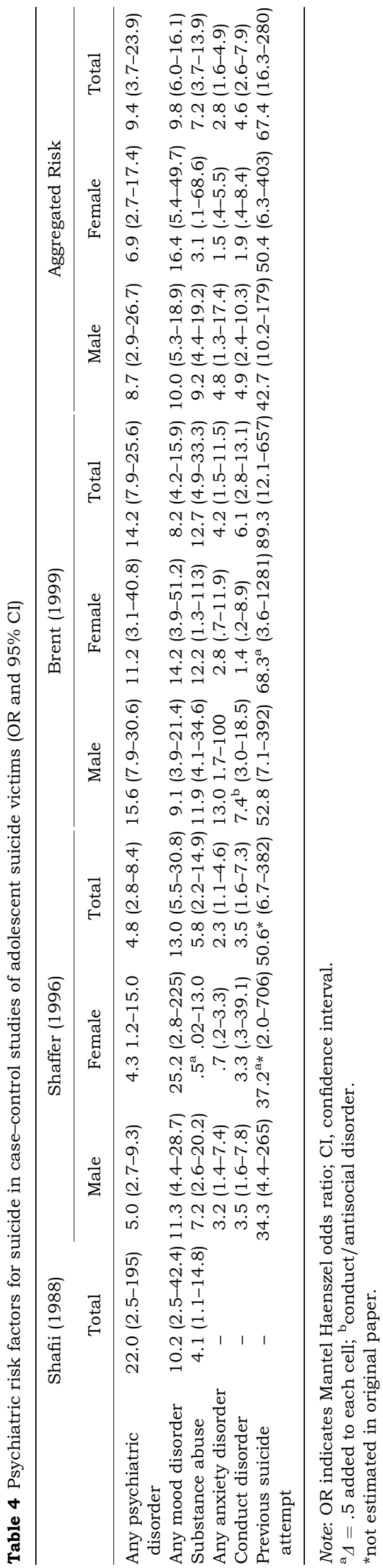

individuals until young adulthood (Allebeck, Allgulander, \& Fisher, 1988; Kotila \& Lonnqvist, 1989; Otto, 1972).

Eating disorders. Shaffer et al. (1996), using parent report, found a $5 \%$ prevalence of eating disorders among young female suicide victims, with no cases reported among female controls, male suicide victims, or male controls. A meta-analysis of suicide in anorexia nervosa shows average mortality rates due to suicide among 14-25-year-olds 8 times higher than expected rates of suicides in the general population (Pompili, Mancinelli, Girardi, Ruberto, \& Tatarelli, 2004).

Eating disorder was associated with a significantly elevated risk of serious suicide attempt in one casecontrol study $(\mathrm{OR}=14.2, \quad 95 \% \quad \mathrm{CI}=1.8-111.3)$ (Beautrais, Joyce, \& Mulder, 1996b). Conversely, female suicide attempters are more likely to have abnormal eating behaviors, including eating disorders (Andrews \& Lewinsohn, 1992; Borowsky et al., 2001).

Psychiatric comorbidity. Psychological autopsy studies have demonstrated that up to $70 \%$ of youth who commit suicide have multiple comorbid disorders, with risk for completed suicide increasing with the number of comorbid disorders (Brent et al., 1999; Shaffer et al., 1996). Similarly, high rates of comorbidity have been reported in studies of youth attempted suicide (Beautrais et al., 1998a; Brent et al., 1993b; Fergusson \& Lynskey, 1995b; Gould et al., 1998; Lewinsohn et al., 1996; Reinherz et al., 1995). The combination of mood, disruptive, and substance abuse disorders is a particularly potent combination for youth suicide and suicidal behavior (Brent et al., 1999; Gould et al., 1998; Lewinsohn et al., 1996; Renaud et al., 1999; Shaffer et al., 1996; Shafii et al., 1988).

Suicide in the apparent absence of disorder. Several studies have investigated suicide in the absence of any mental or substance abuse disorder (Apter et al., 1993; Brent, Perper, Moritz, Baugher, \& Allman, 1993c; Marttunen et al., 1998) (Table 3). Brent et al. (1993c) found that suicide victims without clear psychopathology were more likely than community controls without psychopathology to have had prior suicidal behavior, legal or disciplinary problems, and access to a loaded gun. Marttunen et al. (1998) also found that male suicide victims with no diagnosable psychiatric disorder were more likely than those with a disorder to communicate thoughts for the first time just before suicide, and to experience more disciplinary problems.

While psychiatric disorder is very common in adolescent suicides as a whole, $40 \%$ of suicide completers under the age of 16 do not appear to have a diagnosable psychiatric disorder, with a pattern of 
lower intent and a greater role for the availability of lethal means (Brent et al., 1999; Groholt et al., 1998; Shaffer et al., 1996).

\section{Physical health}

Poor physical health and physical disability were associated with suicidal ideation or behavior in several studies, even after controlling for other risk factors (Dubow, Kausch, Blum, Reed, \& Bush, 1989; Gartrell, Jarvis, \& Derksen, 1993; Grossman, Milligan, \& Deyo, 1991; Rey Gex, Narring, Ferron, \& Michaud, 1998). Some studies suggest an association between suicidal behavior and specific chronic illnesses, such as diabetes and epilepsy (Brent, 1986; Goldston, Kovacs, Ho, Parrone, \& Stiffler, 1994). Functional impairment due to illness or injury has also been associated with future suicide attempt in the prospective study of Lewinsohn et al. (1996).

\section{Intercorrelated health risk behaviors}

Suicidal behavior rarely occurs in isolation. Instead, it most frequently co-occurs with other health risk behaviors, such as binge eating, binge drinking, tobacco use, weapon carrying, and having unprotected sex (King et al., 2001). Common risk factors to all these difficulties are poor parent-child connection, low parental supervision, poor connection between child and school, and association with a deviant peer group (Borowsky et al., 2001; Resnick et al., 1997).

\section{Personality and psychological factors}

Personality disorder/Impulsive aggression. In most psychological autopsy studies, personality disorder was found in about one-third of suicide victims (Table 3). In one controlled study, personality disorder conveyed a 2.9-fold greater risk for suicide, with an 8.5-fold risk conveyed by cluster B (antisocial, borderline, histrionic, narcissistic) disorders after controlling for mood, substance, and conduct disorders (Brent et al., 1994a).

Impulsive aggression, defined as a tendency to react to frustration or provocation with hostility or aggression, is a psychological trait that has been shown to predispose to suicidal behavior (Apter et al., 1995; Beautrais, Joyce, \& Mulder, 1999). A large proportion of child and adolescent suicide attempters exhibit assaultive and aggressive behavior independent of depression (Apter, Bleich, Plutchik, Mendelsohn, \& Tyano, 1988; Brent et al., 1993a; Cohen-Sandler et al., 1982; Pfeffer, Plutchik, \& Mizruchi, 1983). Impulsive aggression has been consistently implicated in the phenomenology, neurobiology, and the familial transmission of suicidal behavior (Brent, Bridge, Johnson, \& Connolly, 1996a; Brent et al., 2002, 2003b; Mann, 1998; Mann, Waternaux, Haas, \& Malone, 1999).
Impulsivity. Several studies reveal an association between impulsivity and adolescent suicidal behavior (Kashden, Fremouw, Callahan, \& Franzen, 1993; Kingsbury, Hawton, Steinhardt, \& James, 1999), although this association was attenuated after controlling for hopelessness, neuroticism, external locus of control, self-esteem, and extroversion (Beautrais et al., 1999). Many adolescent suicide attempts show relatively little planning, and prevention of suicide for the impulsive-subgroup may need to focus on restriction of lethal means (Brent, 1987a; Brent et al., 1999, 1993c; Gunnell, Murray, \& Hawton, 2000).

Neuroticism. Neuroticism, a personality trait characterized by a temperamental tendency to experience a more prolonged and severe range of negative affect in response to stress, has been linked with youth suicide attempts and suicidal ideation (Beautrais et al., 1999; Benjaminsen, Krarup, \& Lauritsen, 1990; Enns, Cox, \& Inayatulla, 2003; Fergusson et al., 2000). Neuroticism has particularly strong discriminative power in case-control studies, is associated with familial suicide, and in one large birth cohort study predicts eventual suicide attempts, even after controlling for other significant risk factors (Beautrais et al., 1999; Fergusson et al., 2000; Roy, 2002).

Self-esteem. Lower self-esteem has been associated with current and future youth suicide attempts, but this association may attenuate after controlling for depression and hopelessness (Fergusson \& Lynskey, 1995a; Lewinsohn et al., 1994; Overholser, Adams, Lehnert, \& Brinkman, 1995).

Hopelessness. Hopelessness is associated with completed and attempted suicide in some community and clinical samples, but this effect is attenuated in some studies after controlling for depression (Goldston et al., 2001; Lewinsohn et al., 1994; Shaffer et al., 1996). Hopelessness has also been associated with suicidal behavior in referred samples in some (Spirito, Overholser, \& Hart, 1991), but not all studies (Brent, Kolko, Allan, \& Brown, 1990; De Wilde, Kienhorst, Diekstra, \& Wolters, 1993).

Perfectionism. In a study of adolescent completed suicide, no association was found between perfectionism and suicide (Shaffer et al., 1996). Perfectionism, particularly the perception that others have unrealistically high expectations, has been reported to be a risk factor for youth suicide attempts (Boergers, Spirito, \& Donaldson, 1998), although in one study the association was attenuated after controlling for psychopathology (Gould et al., 1998).

Sexual orientation. One psychological autopsy study has examined the association between 
non-heterosexual sexual orientation and suicide, and failed to find a difference between cases and controls (Shaffer, Fisher, Hicks, Parides, \& Gould, 1995), although a psychological autopsy procedure may not be sensitive enough to detect issues of sexual orientation.

Community studies have demonstrated that nonheterosexual sexual orientation and same-sex attraction are risk factors for attempted suicide. Putative factors mediating the relationship between gay, lesbian, and bisexual (GLB) orientation and suicide include higher rates of mood and substance abuse disorders, victimization, and family rejection (Borowsky et al., 2001; Fergusson, Horwood, \& Beautrais, 1999; Garofalo, Wolf, Wissow, Woods, \& Goodman, 1999; Remafedi, Farrow, \& Deisher, 1991; Remafedi, French, Story, Resnick, \& Blum, 1998). In one study, youth who reported same-sex sexual orientation were at greater risk than their peers to have attempted suicide, even after controlling for other suicide risk factors like depression, hopelessness, alcohol abuse, and recent victimization (Russell \& Joyner, 2001).

\section{Familial factors in youth suicidal behavior}

Parental psychopathology. Parental psychopathology, including depression, substance abuse, and antisocial behaviors, is a risk factor for youth attempted and completed suicide (Brent, 1995; Brent et al., 1988, 1994b; de Wilde, Kienhorst, Diekstra, \& Wolters, 1992; Fergusson \& Lynskey, 1995a; Gould et al., 1996; Joffe et al., 1988; Pfeffer, Normandin, \& Kakuma, 1994b). Some studies find that parental depression and substance abuse conveys an increased risk for suicide after controlling for psychopathology in the adolescent (Brent et al., 1994b), while others do not (Gould et al., 1996).

Family history of suicidal behavior. There is strong and convergent evidence from adoption, twin, and family studies that suicidal behavior is familial, and perhaps, genetic, and that the liability to suicidal behavior is transmitted in families independently of psychiatric disorder per se (Brent \& Mann, 2005). Probands with suicide attempt showed increased risk of suicide in their family, whereas completed suicide probands showed increased risk of attempt, supporting the view that the phenotype being transmitted was a tendency to suicidal behavior, which varies in lethality (Brent $\&$ Mann, 2005).

A 2-6-fold increased rate of suicidal behavior is found in the relatives of adolescent suicide victims and suicide attempters, even after controlling for higher rates of psychopathology in relatives and offspring in cross-sectional (Agerbo, Nordentoft, \& Mortensen, 2002; Borowsky et al., 2001; Brent et al., 1996a; Gould et al., 1996; Grossman et al., 1991; Johnson, Brent, Bridge, \& Connolly, 1998;
Rey Gex et al., 1998), and prospective studies (Fergusson, Beautrais, \& Horwood, 2003). Highrisk studies comparing the offspring of mood disordered attempters to those of mood disordered non-attempters also report a 5-6-fold increase in offspring suicide attempt, independent of depression and other psychopathology in offspring (Brent et al., 2002; Lieb, Bronisch, Hofler, Schreier, \& Wittchen, 2005). Greater family loading for suicidal behavior was associated with a higher risk and earlier age of onset of suicide attempt in offspring, suggesting that early-onset suicidal behavior may be particularly familial (Brent et al., 2003b). In one high-risk study, transmission of suicidal behavior from parent to child was mediated by the transmission of impulsive aggression (Brent et al., 2003b), which suggests that impulsive aggression may be a behavioral endophenotype that describes a genetic diathesis for suicidal behavior.

\section{Family-environmental factors}

Family constellation. Suicide completers are more likely than community controls to come from nonintact families of origin, although the relationship between divorce and suicidal behavior may be explained by the increased rate of psychopathology in parents whose marriages end in divorce (Brent et al., 1993e, 1994b; Gould et al., 1996; Johnson et al., 2002). Also, the relationship between suicide attempt and marital disruption may be mediated by other psychosocial risk factors such as the quality of the relationship between each of the parents, particularly the father and the child (Beautrais et al., 1996b; Fergusson et al., 2000; Groholt, Ekeberg, Wichstrom, \& Haldorsen, 2000; Tousignant, Bastien, \& Hamel, 1993).

Loss. Several studies have found that loss of a parent to death or divorce, or living apart from one or both biological parents is a significant risk factor for completed suicide (Agerbo et al., 2002; Brent et al., 1994b; Groholt, Ekeberg, Wichstrom, \& Haldorsen, 1997; Shafii et al., 1985). Lewinsohn et al. (1996) found an association between loss of a parent prior to age 12 and multiple suicide attempts. Friends and siblings of adolescent suicide completers showed an increased risk of depression after the death, but no increased risk of suicidal behavior (Brent, Moritz, Bridge, Perper, \& Canobbio, 1996b, 1996c). However, in a longer follow-up of this cohort, persistent traumatic grief was common, and associated with a 5-fold greater likelihood of suicidal ideation, after controlling for depression (Prigerson et al., 1999).

Family relationships. There is a consistent literature linking family discord with youth suicide and suicide attempts (Asarnow \& Carlson, 1988; Brent et al., 1994b; Fergusson \& Lynskey, 1995b; Gould 
et al., 1996; Kerfoot et al., 1996; Kosky, Silburn, \& Zubrick, 1990; Reinherz et al., 1995; Rey Gex et al., 1998; Taylor \& Stansfeld, 1984), although in one study of suicide, this effect was attenuated after controlling for both parental and proband psychopathology (Brent et al., 1994b).

The quality of the parent-child relationship is also an important factor in suicide and suicidal behavior (Wagner, Cole, \& Schwartzman, 1995). Gould et al. (1996) found that poor communication with father was a significant risk factor for suicide in older adolescents, even after adjusting for other factors. Tousignant et al. (1993) also found that a negative father-child relationship had a key and enduring role in suicidal behavior of adolescents and young adults. Lack of perceived parental support or availability is also associated with adolescent attempted suicide (Fergusson \& Lynskey, 1995b; Yuen et al., 1996). Conversely, family cohesion, positive parentchild connection, spending time together, parental supervision, and high parental academic and behavior expectations were protective (Borowsky et al., 1999; Resnick et al., 1997).

Maltreatment. Physical and sexual abuse, particularly the latter, are strongly associated with attempted and completed suicide (Borowsky et al., 1999; Brent et al., 1999; Fergusson, Horwood, \& Lynskey, 1996; Kosky et al., 1990; Molnar, Berkman, \& Buka, 2001; Pfeffer et al., 1994a; Wagner et al., 1995). The population attributable risk (PAR) of sexual abuse for suicide attempts in adolescents in population studies has been estimated to be 16.6$19.5 \%$, with much greater risk for suicidal behavior following more serious sexual abuse, such as intercourse (J. Brown, Cohen, Johnson, \& Smailes, 1999; Fergusson et al., 1996; Johnson et al., 2002). While the main effect of sexual abuse on suicidal behavior appears to be mediated through an increased risk for psychopathology (Fergusson et al., 2000), there may be an independent effect for both risk and early age of onset of suicide attempt, even after controlling for increased risk for psychopathology and other factors (Borowsky et al., 1999; Grossman et al., 1991; Molnar et al., 2001; Rey Gex et al., 1998).

The effects of child maltreatment and its relationship to suicide are compounded by the intergenerational transmission of abuse. The familial transmission of suicidal behavior is more likely if the attempting parent had been sexually abused as a child, in part because parental history of abuse makes the child more likely to be abused, which then increases his or her risk for suicide attempt (Brent et al., 2003b). Thus, abuse is not only a risk factor for suicidal behavior for those abused as children, but also for their offspring.

'Drifting.' Youth who are disconnected from major support systems (school, work, and family) appear to be at very high risk for suicide, particularly in the context of other risk factors that are likely to contribute to their 'drifting' status (Gould et al., 1996). Living apart from parents is a risk factor for attempted suicide, even after adjusting for other risk factors (Rey Gex et al., 1998). Adolescents on the verge of dropping out have many indicators of suicidal risk (Eggert, Thompson, Herting, \& Nicholas, 1995). Furthermore, the risk of attempted suicide increases among school dropouts or after a period of absence from school (Beautrais et al., 1996b; Wunderlich, Bronisch, \& Wittchen, 1998). Conversely, positive connection to school and academic achievement appears to be protective against suicidal behavior (Borowsky et al., 1999; Resnick et al., 1997).

\section{Biological factors}

The neurobiology of suicide and suicidal behavior is a well-researched area, but little work has been done in younger samples (Mann, 2003). The most consistent biological finding has been a relationship between altered central serotonin, as assessed by neuroendocrine challenge tests and cerebrospinal fluid (CSF) studies in attempters, and by receptor binding in post-mortem studies. Low CSF 5-hydroxyindoleacetic acid (5HIAA), a metabolite of serotonin, has been associated with impulsive aggression and suicidal behavior across psychiatric conditions in adults (Mann, 1998). Greenhill et al. (1995) found an association between serotonin measures and medically serious attempts within a small sample of adolescent suicide attempter inpatients with MDD. In one study of preadolescent boys, low CSF 5-HIAA was not correlated with aggression (Kruesi et al., 1990), but predicted aggression upon follow-up, after the sample had entered puberty (Kruesi et al., 1992). Altered response to fenfluramine challenge, an alternative measure of central serotonergic function, has been associated with poor home environment, aggression, and depression, but not with suicidal behavior (Birmaher et al., 1997; Pine et al., 1997). However, among adults, greater alteration in central serotonin function has been found to be most marked in attempters less than age 30 (Malone, Corbitt, Li, \& Mann, 1996).

Pandey and colleagues $(1997,2004,2002)$, in a series of post-mortem studies, have shown that adolescent suicide completers compared with deceased controls without disorder have increased $5-\mathrm{HT}_{2 \mathrm{a}}$ binding, decreased protein kinase A (PKA) and $\mathrm{C}(\mathrm{PKC})$ activity, down regulation of $\mathrm{CREB}$, and increased activity of brain-derived neurotropic factor (BDNF) in the prefrontal cortex and hippocampus (except PKA, which was not different in hippocampus). These findings are similar to those reported for adults, which suggest involvement of the serotonin system as well as systems involved in cell signaling and signal modulation. 
Zalsman and colleagues (2001) examined the allelic association of the serotonin transporter (5-HTTLPR) with suicidal behavior and related traits in a sample of Israeli suicidal inpatients, and found no significant relationship. However, patients with the $l l$ genotype were significantly different than patients with the ls genotype on a measure of trait violence. In a prospective-longitudinal study of a New Zealand birth cohort, Caspi and colleagues (2003) found that the $s$ allele of 5-HTTLPR, in the presence of stressful life events, resulted in increased rates of depression and suicidality.

\section{Exposure to suicide}

Clusters and contagion. Gould et al. (1990a) have demonstrated that a small but statistically significant number of adolescent suicide completions occur in time-space clusters, consistent with the mechanisms of contagion and imitation. These effects have been reported both for clusters of completed (Gould et al., 1990a) and attempted suicide (Gould, Petrie, Kleinman, \& Wallenstein, 1994), and appear limited to adolescents and young adults (Brent et al., 1989; Gould, 2001; Gould et al., 1994; Gould, Wallenstein, Kleinman, O'Carroll, \& Mercy, 1990b; Phillips \& Carstensen, 1986).

Media influences. Publicity about suicide, whether through newspaper accounts, television news reports, or fictional docudramas, is followed by an increase in the rate of suicide and suicide attempt (Gould, 2001; Gould \& Shaffer, 1986; Phillips \& Carstensen, 1986; Schmidtke \& Schaller, 2000; Stack, 2000). Factors that increase the likelihood of imitation include the amount of publicity and the notoriety of the victim (Gould, 2001; Stack, 2003). Presenting suicide in a factual light (i.e., related to mental disorder) as compared to romanticizing suicide was associated with a lower risk of imitation (Stack, 2005). There is some evidence that imitation may be method-specific (Schmidtke \& Schaller, 2000).

Prospective studies of exposure. Brent et al. (1996c) found no evidence of an increased incidence of suicidal behavior in the friends exposed to the suicide of an adolescent peer, compared to unexposed community controls, despite increased risk of depression and PTSD. Similarly, Hazell and Lewin (1993) in an Australian sample found that adolescents exposed to an adolescent suicide did not show an increased rate of suicidal behavior in comparison to unexposed adolescent controls. On the other hand, Ho and colleagues (2000), in a cross-sectional study, found that peers of Chinese adolescent suicide attempters and completers had higher rates of suicidal behavior than unexposed controls, even after controlling for age, sex, and potential risk factors. Several studies have found an association between attempted suicide and having a friend who has made a suicide attempt, although this could be accounted for by assortative friendships rather than exposure (Grossman et al., 1991; Lewinsohn et al., 1994; Rey Gex et al., 1998). However, Lewinsohn et al. (1994) found that a recent suicide attempt by a friend was a significant predictor of a future suicide attempt, even after controlling for depression and psychosocial risk factors.

\section{Availability of lethal agents}

Case-control studies. A series of case-control studies has demonstrated a clear and consistent association between firearms in the home and completed suicides, with a particularly high risk of suicide conveyed by guns in the homes of American adolescents and young adults (Brent et al., 1988, 1993f; Kellermann et al., 1992; Shah, Hoffman, Wake, \& Marine, 2000; Wiebe, 2003), although these results were not replicated in New Zealand (Beautrais, Joyce, \& Mulder, 1996a). If a gun is present in the home, it is highly likely to be used as the method of suicide, whereas, in the absence of a firearm in the home, this method is infrequently chosen (Brent et al., 1991, 1993f; Kellermann et al., 1992). Keeping a gun locked, unloaded, storing ammunition locked, and in a separate location are each associated with a further reduction in firearm risk (Grossman et al., 2005).

Cross-country comparative studies. A series of cross-sectional studies have shown a relationship between stricter gun control legislation and firearms availability and lower suicide rates (Killias, 1993; Krug, Dahlberg, \& Powell, 1996; Sloan, Rivara, Reay, Ferris, \& Kellermann, 1990). In one cross-national comparison, the overall suicide rates in two similar cities, Seattle and Vancouver, were similar but the suicide rate among 15-24-year-olds was 40\% higher in Seattle, a difference accounted for almost entirely by a 10-fold excess rate of firearm-related suicide in that city (Sloan et al., 1990). This supports the view that gun availability may be particularly salient for youth suicide.

Quasi-experimental studies. Quasi-experimental studies that have examined the impact of changes in firearms legislation on suicide rates provide modest support for a role for greater restrictiveness of gun legislation in the reduction of the suicide rate, sometimes without compensatory method substitution (Cantor \& Slater, 1995; Carrington \& Moyer, 1994; Cummings, Grossman, Rivara, \& Koepsell, 1997; Loftin, McDowall, Wiersema, \& Cottey, 1991; Webster et al., 2004).

The availability of potentially lethal drugs may also increase the risk of suicide or at least increase the medical lethality of an attempt (Brent, 1987a). Legislation restricting the amount of drug available per 
purchase and the use of blister packs requiring individual pills to be removed from a card with each pill in its own 'bubble' (rather than sold as loose tablets) may reduce the morbidity and mortality due to paracetamol overdose (Chan, 1996; Hawton et al., 2001, 1996). Restriction of drug content per purchase resulted in a 4-fold lower fatality from overdose in France, compared to England (Gunnell et al., 1997a). The introduction of blister packaging of paracetamol in the UK was associated with a $21 \%$ reduction in overdoses and a $64 \%$ reduction in severe overdoses (Turvill, Burroughs, \& Moore, 2000).

\section{Intervention}

There is a paucity of clinical trials studying the treatment of adolescent suicidal behavior. Most treatment studies of depressed adolescents exclude suicidal adolescents and/or do not report impact of treatment on suicidal ideation and behavior. In one psychotherapy trial that included suicidal, depressed adolescents, whereas cognitive behavioral therapy was superior to family therapy and supportive therapy with regard to resolution of depressive symptomatology, there were no group differences with regard to suicidality (Brent et al., 1997). In the Treatment of Adolescent Depression Study (TADS), whereas fluoxetine was markedly superior to placebo in the treatment of depression, there were no differences in the rate of reduction of suicidal ideation, although there was a significant reduction in all groups (March et al., 2004). There was an approximately twofold increase in suiciderelated adverse events in medication versus placebo in TADS (FDA 2004; March et al., 2004). The FDA recently conducted pooled analyses of short-term (4 to 16 weeks) placebo-controlled trials of nine antidepressant drugs (SSRIs and others) in children and adolescents with MDD, OCD, or other psychiatric disorders and found an increased risk of suicidality (suicidal ideation or attempt) in those receiving antidepressants (FDA 2004; March et al., 2004). While no subject in any of these studies committed suicide and very few attempted suicide, the average risk of such events on drug was $4 \%$, twice the placebo risk of $2 \%$ (odds ratio $=1.8,95 \%$ confidence interval $=1.1-2.8$.

Harrington et al. (1998) found that home-based family therapy was not different than treatment as usual for the treatment of adolescent suicide attempters, except in the subgroup of non-depressed adolescents, in which there was a reduction in suicide attempts. Wood et al. (2001) found that a skills-based group treatment was better than treatment as usual for reduction in repetitive self-harm. RotheramBorus et al. $(2000,1996 b)$ found that emergency room psychoeducation and treatment session increased compliance with a brief cognitive behavioral family therapy for adolescent suicide attempters, which in turn was related to better mental health outcomes in mothers and daughters. One study reported that multi-systemic therapy (MST) was superior to hospitalization for prevention of suicide attempts, but nearly half of the MST group were also hospitalized, making interpretation of the findings difficult (Huey et al., 2004). One study to enhance the social network of suicidal adolescents found a small impact on suicidal ideation and mood for females, but not males (King et al., in press). One quality improvement study in adolescents with depression treated in primary care showed that collaborative care improved depression more than usual care, and showed a trend toward reducing suicidal ideation or attempts at 6-month follow-up (Asarnow et al., 2005). Other studies are either too small, or quasiexperimental, but have examined skills-based therapy, dialectical-behavior therapy (DBT), without definitive results (Donaldson, Spirito, \& EspositoSmythers, 2005; Katz, Cox, Gunasekara, \& Miller, 2004; Miller, Rathus, Linehan, Wetzler, \& Leigh, 1997). One school-based prevention program that taught problem-solving skills and enhanced schoolchild connections found that overall, there were improvements in suicide risk factors, but no difference between the experimental program and a brief suicide screening followed by case management (Eggert et al., 1995).

\section{Clinical management}

Service use. The rate of mental health treatment prior to suicide varies tremendously between studies, probably reflecting national differences in access and cost of services (Luoma, Martin, \& Pearson, 2002). In two US studies, only $7-20 \%$ of adolescent suicide completers had been seen for mental health treatment in the previous 1-3 months prior to the suicide (Brent et al., 1993; Shaffer et al., 1996). Whites, females, and those with either schizophrenia or disruptive disorders were most likely to have been treated before the suicide (Marttunen et al., 1992; Shaffer et al., 1996). Slap et al. (1989) found that adolescent suicide attempters were 2.5 times more likely to depend on the emergency room for routine care than were adolescents hospitalized for acute illnesses unrelated to injuries or ingestions, even after controlling for socioeconomic status.

Recognition. In general, primary care physicians are specific but not sensitive in their detection of psychosocial difficulties (Dulcan et al., 1990). In one study of primary care physicians, most providers reported $(77 \%)$ not routinely screening for adolescent suicidality and other suicide risk factors, despite having a high rate $(47 \%)$ of encounters with adolescent suicide attempters in the previous year (Frankenfield et al., 2000).

Inpatient hospitalization. Hospitalization is considered a linchpin in the management of the acutely 
suicidal patient (Shaffer \& Pfeffer, 2001). While the hospital environment is viewed as a safe place to deal with the suicidal crisis, there are no empirical data to support the efficacy of this very costly intervention (Greenhill \& Waslick, 1997; Shaffer \& Pfeffer, 2001). Hospitalized patients are at particularly high risk for suicide reattempt, due to the same factors that led to their hospitalization, with the highest risk period occurring in the transition from inpatient to lesser levels of care (Appleby, Dennehy, Thomas, Faragher, \& Lewis, 1999; Huey et al., 2004; Taiminen, KallioSoukainen, Nokso-Koivisto, Kaljonen, \& Kelenius, 1998).

Transition from inpatient to less restrictive levels of care. Among adolescent suicide attempters, compliance with aftercare was best achieved when hospital staff scheduled the initial appointment with the therapist to whom the adolescent was being referred (Granboulan, Roudot-Thoraval, Lemerle, \& Alvin, 2001). Education has also been found to be helpful in improving adherence (Rotheram-Borus et al., 1996a).

Because of the high suicide risk following discharge from hospital, particularly in non-adherent patients, Carter et al. (2005) studied the impact of sending postcards over a year period following discharge of suicide attempters 16 years of age or older in a randomized trial. Over the first year of follow-up, the intervention group had fewer suicide attempts, and used few hospital days.

School-based programs. Several controlled studies that have examined students' help-seeking behavior following suicide awareness programs have failed to find a positive effect, with some evidence that the students most at risk became distressed because of the intervention, and less likely to seek care (Shaffer, Garland, Vieland, Underwood, \& Busner, 1991; Shaffer et al., 1990; Spirito, Overholser, Ashworth, Morgan, \& Benedict-Drew, 1988; Vieland, Whittle, Garland, Hicks, \& Shaffer, 1991). These findings resulted in a shift in school-based programs from 'suicide awareness' to a more generic emphasis on mental health (Kalafat \& Elias, 1994). Comprehensive direct case-finding via systematic screening and subsequent clinical referral may be a more effective means of identifying suicidal youth, but the efficacy of this approach has not yet been established (Shaffer \& Gould, 2000; Shaffer et al., 2004). However, it is now well established that there are no adverse effects from direct screening of students for suicidal behavior (Gould et al., 2005).

Safety plans and no harm contracts. The negotiation of the safety plan is considered one of the most critical parts of the assessment and treatment of suicidality, and involves the securing of lethal agents (e.g., firearms), a review of precipitants that led to the suicidal crisis, and brief training in emotional regulation (Brent, 1997). The no-harm contract, an important component of safety plans, is an agreement between the adolescent, parents and clinician that should the adolescent have suicidal impulses, he/she will inform a responsible adult and/or call the clinician or emergency room, and a method for coping with suicidal urges, should they occur (Drye, Goulding, \& Goulding, 1973; Rotheram-Borus \& Bradley, 1990, 1991). No-harm contracts may be either verbal or written. Clinical guidelines caution against using no-harm contracts as a pre-condition to coerce adolescent patients, since it may obscure the adolescent's true suicidal risk status (Shaffer \& Pfeffer, 2001).

There is virtually no empirical evidence to support the effectiveness of safety plans in general, and noharm contracts in particular (Kelly \& Knudson, 2000; Reid, 1998; Shaffer \& Pfeffer, 2001; Stanford et al., 1994). The only data to support this approach is a quasi-experimental study that showed a reduction in suicide attempts among youth in a runaway shelter after the staff implemented a brief assessment and emotion regulation training for youth judged to be at risk for suicide attempts (Rotheram-Borus \& Bradley, 1991).

Means restriction counseling. Despite broad acceptance of the importance of means restriction, this aspect of suicide risk management has not been subject to rigorous evaluation. Studies in emergency room settings document the low prevalence of means restriction education for suicidal patients (McManus et al., 1997; Wislar et al., 1998). While one emergency room pilot study suggests that after counseling, parents are much more likely to remove firearms from the home (Kruesi et al., 1999), studies in psychiatric and pediatric outpatient settings have not demonstrated a palpable effect of parent education (Brent, Baugher, Birmaher, Kolko, \& Bridge, 2000; Grossman et al., 2000). The lack of success may be due to insisting on removal of the gun rather than securing it, not speaking directly to the gun owner, and not ascertaining the perceived risks of removing the gun (Brent \& Bridge, 2003).

\section{Model of suicidal behavior}

On the basis of the extant literature, we present a developmental-transactional model of youth suicidal behavior, which has the heuristic advantage that one can theoretically identify precursors of suicidal behavior and use this model to develop interventions to attenuate suicide potential (Figure 1). As has been well articulated by others (Brent \& Mann, 2003a; Mann et al., 1999; Shaffer \& Pfeffer, 2001), suicidal behavior may arise through an interaction of two sets of vulnerabilities - major psychiatric disorder, most commonly mood disorder, and a tendency to impulsive aggression, which in turn may have 


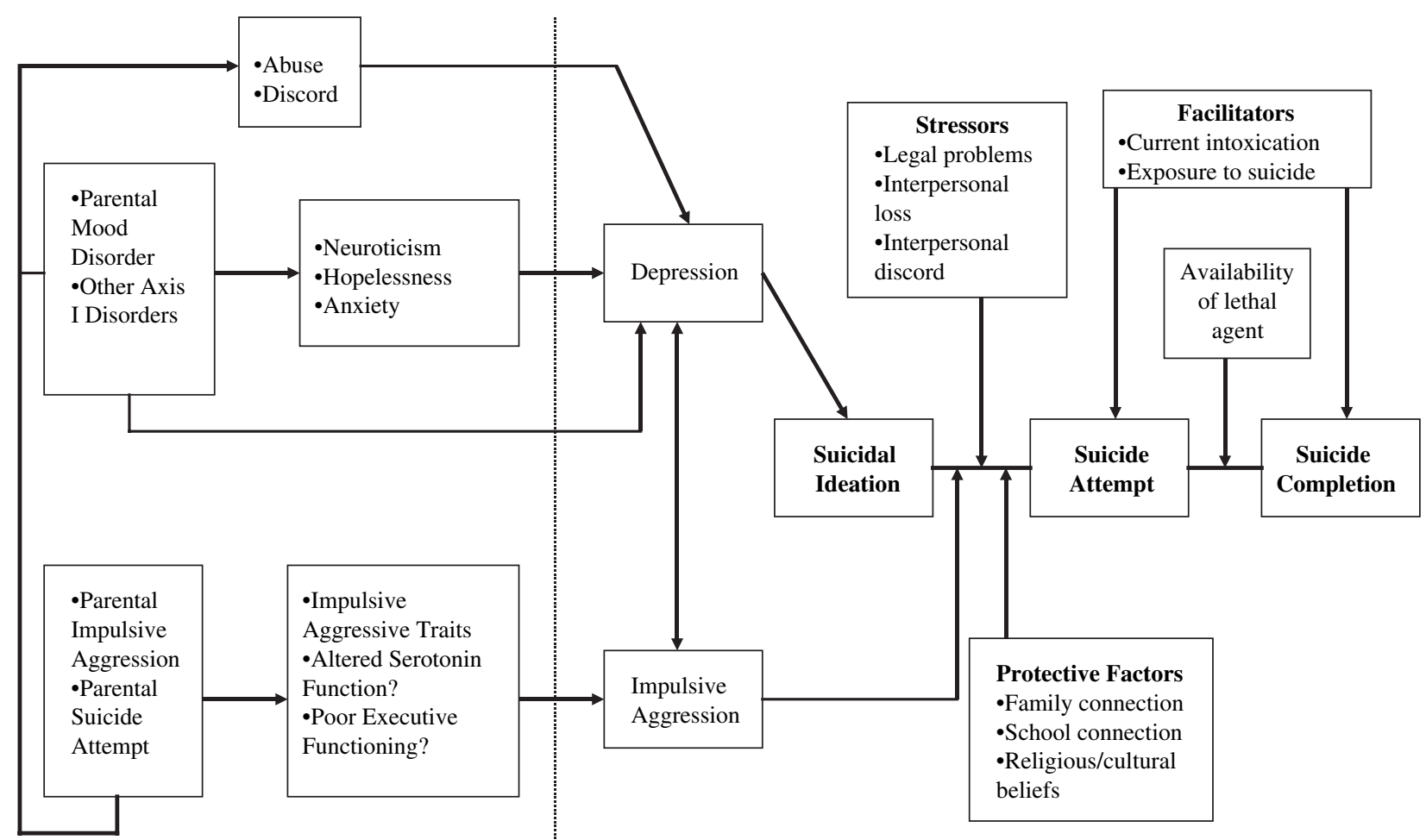

Before Puberty

After Puberty

Figure 1 Developmental-transactional model of youth suicidal behavior

neurobiological correlates such as impaired executive functioning and altered serotonin metabolism in the ventral prefrontal cortex.

While each domain is presented separately, in reality, these domains are not orthogonal and exert bi-directional influence. For example, impulsive aggression in a child may increase the likelihood of depression, and conversely, early-onset depression may lead to emotion-regulation difficulties manifesting as impulsive aggression (Brent et al., 2004b; Jaffee et al., 2002; Lewinsohn, Gotlib, \& Seeley, 1997).

Because so many of the factors involved in earlyonset suicidal behavior are familial (either genetic or environmental), this model begins with parental risk factors, and depicts the transmission of risk factors from parent to child. Suicidal behavior is rare prior to the onset of puberty, in large part because mood disorder, one of the important components of suicidal risk, is rare prepubertally. Precursors of mood disorder that are likely to be manifested prepubertally include impulsive aggression, neurotic traits, anxiety, and cognitive distortions such as pessimism. After puberty, when mood disorder and impulsive aggression co-occur, the liability to suicidal behavior increases dramatically. While suicidal behavior can occur in the absence of either set of vulnerabilities, the co-occurrence of both sets makes suicidal behavior much more likely to ensue.

Suicidal ideation is a frequent precursor to suicide attempt, but is much more likely to 'progress' to actual behavior in the presence of impulsive aggression. In addition, the co-occurrence of certain acute stressors, such as legal/disciplinary problems and interpersonal conflict or loss, may make it more likely that a suicide ideator will act on their ideation. Potential 'facilitators' of suicidal behavior include intoxication and exposure to suicidal behavior (Brent, 1987a; Gould et al., 1998; Lewinsohn et al., 1994). Availability of a lethal agent, such as a gun, can make the attempt more likely to result in fatality. Countering facilitators are protective factors that reduce the likelihood of onset and progress of ideation to attempt, namely a positive parent-child connection, active parental supervision, high behavioral and academic expectations, positive school-child connection, and religious and cultural beliefs against suicide (Borowsky et al., 2001; Resnick et al., 1997).

\section{Confluence of risk factors}

The mantra of suicide prevention over the past decade has been to improve the identification and treatment of psychiatric disorders. However, the single biggest risk factor for completed suicide is a previous suicide attempt, even after controlling for psychiatric disorder. Suicidal and suicide attempting patients are frequently excluded from clinical trials, making it impossible to know if treatment of psychiatric disorder will reduce risk for reattempt in the highest risk populations. Nonetheless, given that 
chronicity, severity, and complexity (e.g., comorbidity) of psychiatric disorder are all related to suicidal risk, it seems likely that earlier identification and earlier symptomatic relief is an important component of the prevention and treatment of youth suicidal behavior.

Consequently, given the paucity of treatment studies that specifically target suicide attempters, such studies are indicated. There are now some promising psychosocial treatments that involve cognitive, emotion-regulation, and interpersonal approaches that should be tested in younger populations (Brown et al., 2005; Guthrie et al., 2001; Linehan, Armstrong, Suarez, Allmon, \& Heard, 1991). Moreover, pharmacological approaches should also be considered, particularly for those youth with recurrent suicidal behavior, which target aggressive and emotional dysregulation such as lithium, other mood stabilizers, and atypical neuroleptics.

In light of the intercorrelation of different health risk factors, such as binge eating, binge drinking, weapon carrying, having unprotected sex, and suicidal behavior, a broader focus on interventions that target common vulnerabilities is warranted (Brent, 2004a). Correlative studies suggest that protective factors common to these health risk behaviors are parent-child connection, supervision, and expectations, and school connection (Resnick et al., 1997). Interventions that increase these protective factors may indeed be helpful in targeting young people with multiple risk behaviors.

It may be possible to identify families in whom it is highly likely that a child will become a suicide attempter, such as a child with a parent with a mood disorder and history of suicide attempt (Brent et al., 2002, 2003b, 2004b). Interventions should be developed to attenuate risk for familial transmission of suicidal behavior.

While it is important to improve our treatments in high-risk patients who seek services, one must recognize that the majority of suicide completers and attempters never come to the attention of specialty mental health care (Brent et al., 1993; Shaffer et al., 1996). Many of these young people have other health service system contacts, such as emergency rooms, juvenile detention, unemployment offices, schools, and child welfare (Gray et al., 2002; Slap et al., 1989). Better linkages to mental health and on-site delivery of services may serve to bring help to these young people.

It is also important to evaluate some of the 'tried and true' aspects of the management of suicidal youth. Can improved continuity of care reduce suicidal risk associated with discharge from hospital? Are there elements of a safety plan that are helpful or harmful? Is hospitalization, particularly involuntary commitment, likely to be of benefit? Do hotlines reach the people who need help and do they make a difference? Do postventions in schools actually reduce the risk of contagion?

In younger adolescents, for whom completed suicide is less a function of psychopathology and intent, and more a matter of access to lethal agents, interventions to reduce access to guns and other lethal agents may reduce the burden of suicide. However, prior efforts at getting parents to remove firearms have had mixed results at best (Brent et al., 2000; Grossman et al., 2000; Kruesi et al., 1999). Therefore, further research is indicated in finding acceptable methods for getting parents to adhere to better safety practices.

Finally, further research on the genetics and neurobiology of early-onset suicidal behavior and related endophenotypes, such as impulsive aggression and their interaction with stressful life events like abuse, is needed. Neuroimaging provides the opportunity to examine correlates of poor problemsolving, emotional reactivity, and impulsivity that characterize many young suicide attempters. These studies in turn may both help to clarify the phenotypes that are most profitable to study genetically, and provide further guidance for treatment.

\section{Acknowledgements}

This work was supported by NIMH grants P30 MH66371, T32 MH18951 (Dr. Brent) and K01 MH69948 (Dr. Bridge).

Holly Irvine, B.S, provided invaluable research assistance. This paper is dedicated to the memory of Professor Richard Harrington.

\section{Correspondence to}

David A. Brent, Western Psychiatric Institute and Clinic, Child and Adolescent Psychiatry, 3811 O'Hara Street, BFT 311, Pittsburgh, PA 15213-2592, USA; Tel: (412) 246-5596; Fax: (412) 246-5344; Email: brentda@upmc.edu

\section{References}

Agerbo, E., Nordentoft, M., \& Mortensen, P.B. (2002). Familial, psychiatric, and socioeconomic risk factors for suicide in young people: Nested case-control study. British Medical Journal, 325, 74.

Allebeck, P., \& Allgulander, C. (1990). Suicide among young men: Psychiatric illness, deviant behaviour and substance abuse. Acta Psychiatrica Scandinavica, 81, 565-570.

Allebeck, P., Allgulander, C., \& Fisher, L.D. (1988). Predictors of completed suicide in a cohort of 50,465 young men: Role of personality and deviant behaviour. British Medical Journal, 297, 176-178.

Anderson, R.N. (2002). Deaths: Leading causes for 2000. National Vital Statistics Reports 50(16). Hyattsville, MD: National Center for Health Statistics. 
Andrews, J.A., \& Lewinsohn, P.M. (1992). Suicidal attempts among older adolescents: Prevalence and co-occurrence with psychiatric disorders. Journal of the American Academy of Child and Adolescent Psychiatry, 31, 655-662.

Appleby, L., Dennehy, J.A., Thomas, C.S., Faragher, E.B., \& Lewis, G. (1999). Aftercare and clinical characteristics of people with mental illness who commit suicide: A case-control study. Lancet, 353, 1397-1400.

Apter, A., Bleich, A., King, R.A., Kron, S., Fluch, A., Kotler, M., et al. (1993). Death without warning? A clinical postmortem study of suicide in 43 Israeli adolescent males. Archives of General Mendelsohn, S., \& Tyano, S. (1988). Suicidal behavior, depression, and conduct disorder in hospitalized adolescents. Journal of the American Academy of Child and Adolescent Psychiatry, 27, 696-699.

Apter, A., Bleich, A., Plutchik, R., Mendelsohn, S., \& Tyano, S. (1988). Suicidal behavior, depression, and conduct disorder in hospitalized adolescents. Journal of the American Academy of Child and Adolescent Psychiatry, 27, 696-699.

Apter, A., Gothelf, D., Orbach, I., Weizman, R., Ratzoni, G., Har-Even, D., et al. (1995). Correlation of suicidal and violent behavior in different diagnostic categories in hospitalized adolescent patients. Journal of the American Academy of Child and Adolescent Psychiatry, 34, 912-918.

Asarnow, J.R., \& Carlson, G. (1988). Suicide attempts in preadolescent child psychiatry inpatients. Suicide and Life-Threatening Behavior, 18, 129-136.

Asarnow, J.R., Jaycox, L.H., Duan, N., LaBorde, A.P., Rea, M.M., Murray, P., et al. (2005). Effectiveness of a quality improvement intervention for adolescent depression in primary care clinics: A randomized controlled trial. Journal if the American Medical Association, 293, 311-319.

Beautrais, A.L. (2000a). Methods of youth suicide in New Zealand: Trends and implications for prevention. Australian and New Zealand Journal of Psychiatry, 34, 413-419.

Beautrais, A.L. (2000b). Risk factors for suicide and attempted suicide among young people. Australian and New Zealand Journal of Psychiatry, 34, 420-436.

Beautrais, A.L. (2001a). Child and young adolescent suicide in New Zealand. Australian and New Zealand Journal of Psychiatry, 35, 647-653.

Beautrais, A.L., Joyce, P.R., \& Mulder, R.T. (1996a). Access to firearms and the risk of suicide: A case control study. Australian and New Zealand Journal of Psychiatry, 30, 741-748.

Beautrais, A.L., Joyce, P.R., \& Mulder, R.T. (1996b). Risk factors for serious suicide attempts among youths aged 13 through 24 years. Journal of the American Academy of Child and Adolescent Psychiatry, 35, 1174-1182.

Beautrais, A.L., Joyce, P.R., \& Mulder, R.T. (1998a). Psychiatric illness in a New Zealand sample of young people making serious suicide attempts. New Zealand Medical Journal, 111, 44-48.

Beautrais, A.L., Joyce, P.R., \& Mulder, R.T. (1999). Personality traits and cognitive styles as risk factors for serious suicide attempts among young people. Suicide and Life-Threatening Behavior, 29, 37-47.
Beck, R.W., Morris, J.B., \& Beck, A.T. (1974). Crossvalidation of the Suicidal Intent Scale. Psychological Reports, 34, 445-446.

Benjaminsen, S., Krarup, G., \& Lauritsen, R. (1990). Personality, parental rearing behaviour and parental loss in attempted suicide: A comparative study. Acta Psychiatrica Scandinavica, 82, 389-397.

Berlin, I.N. (1987). Suicide among American Indian adolescents: An overview. Suicide and Life-Threatening Behavior, 17, 218-232.

Birmaher, B., Kaufman, J., Brent, D.A., Dahl, R.E., Perel, J.M., al-Shabbout, M., et al. (1997). Neuroendocrine response to 5-hydroxy-L-tryptophan in prepubertal children at high risk of major depressive disorder. Archives of General Psychiatry, 54, 11131119.

Boergers, J., Spirito, A., \& Donaldson, D. (1998). Reasons for adolescent suicide attempts: Associations with psychological functioning. Journal of the American Academy of Child and Adolescent Psychiatry, 37, 1287-1293.

Boothroyd, L.J., Kirmayer, L.J., Spreng, S., Malus, M., $\&$ Hodgins, S. (2001). Completed suicides among the Inuit of northern Quebec, 1982-1996: A case-control study. Canadian Medical Association Journal, 165, 749-755.

Borowsky, I.W., Ireland, M., \& Resnick, M.D. (2001). Adolescent suicide attempts: Risks and protectors. Pediatrics, 107, 485-493.

Borowsky, I. W., Resnick, M. D., Ireland, M., \& Blum, R. W. (1999). Suicide attempts among American Indian and Alaska Native youth: Risk and protective factors. Archives of Pediatrics and Adolescent Medicine, 153, 573-580.

Brent, D.A. (1986). Overrepresentation of epileptics in a consecutive series of suicide attempters seen at a children's hospital, 1978-1983. Journal of the American Academy of Child Psychiatry, 25, 242246.

Brent, D.A. (1987a). Correlates of the medical lethality of suicide attempts in children and adolescents. Journal of the American Academy of Child and Adolescent Psychiatry, 26, 87-91.

Brent, D.A. (1995). Risk factors for adolescent suicide and suicidal behavior: Mental and substance abuse disorders, family environmental factors, and life stress. Suicide and Life-Threatening Behavior, 25 Suppl., 52-63.

Brent, D.A. (1997). The aftercare of adolescents with deliberate self-harm. Journal of Child Psychology and Psychiatry, 38, 277-286.

Brent, D.A. (2004a). The rewards of reducing risk. Archives of Pediatrics and Adolescent Medicine, 158, 824-825.

Brent, D.A., Baugher, M., Birmaher, B., Kolko, D.J., \& Bridge, J. (2000). Compliance with recommendations to remove firearms in families participating in a clinical trial for adolescent depression. Journal of the American Academy of Child and Adolescent Psychiatry, 39, 1220-1226.

Brent, D.A., Baugher, M., Bridge, J., Chen, T., \& Chiappetta, L. (1999). Age- and sex-related risk factors for adolescent suicide. Journal of the American Academy of Child and Adolescent Psychiatry, 38, 1497-1505. 
Brent, D.A., Bridge, J., Johnson, B.A., \& Connolly, J. (1996a). Suicidal behavior runs in families. A controlled family study of adolescent suicide victims. Archives of General Psychiatry, 53, 1145-1152.

Brent, D.A., \& Bridge, J.A. (2003). Firearms availability and suicide: Evidence, interventions, and future directions. American Behavioral Scientist, 46, 11921210.

Brent, D.A., Holder, D., Kolko, D., Birmaher, B., Baugher, M., Roth, C., et al. (1997). A clinical psychotherapy trial for adolescent depression comparing cognitive, family, and supportive therapy. Archives of General Psychiatry, 54, 877-885.

Brent, D.A., Johnson, B., Bartle, S., Bridge, J., Rather, C., Matta, J., et al. (1993a). Personality disorder, tendency to impulsive violence, and suicidal behavior in adolescents. Journal of the American Academy of Child and Adolescent Psychiatry, 32, 69-75.

Brent, D.A., Johnson, B.A., Perper, J., Connolly, J., Bridge, J., Bartle, S., et al. (1994a). Personality disorder, personality traits, impulsive violence, and completed suicide in adolescents. Journal of the American Academy of Child and Adolescent Psychiatry, 33, 1080-1086.

Brent, D.A., Kerr, M.M., Goldstein, C., Bozigar, J., Wartella, M., \& Allan, M.J. (1989). An outbreak of suicide and suicidal behavior in a high school. Journal of the American Academy of Child and Adolescent Psychiatry, 28, 918-924.

Brent, D.A., Kolko, D.J., Allan, M.J., \& Brown, R.V. (1990). Suicidality in affectively disordered adolescent inpatients. Journal of the American Academy of Child and Adolescent Psychiatry, 29, 586-593.

Brent, D.A., Kolko, D.J., Wartella, M.E., Boylan, M.B., Moritz, G., Baugher, M., et al. (1993b). Adolescent psychiatric inpatients' risk of suicide attempt at 6month follow-up. Journal of the American Academy of Child and Adolescent Psychiatry, 32, 95-105.

Brent, D.A., \& Mann, J.J. (2003a). Familial factors in adolescent suicidal behavior. In R.A. King \& A. Apter (Eds.), Suicide in children and adolescents (pp. 86117). Cambridge: Cambridge University Press.

Brent, D.A., \& Mann, J.J. (2005). Family genetic studies, suicide, and suicidal behavior. American Journal of Medical Genetics Part C (Semin. Med. Gen.), 133C, 13-24.

Brent, D.A., Moritz, G., Bridge, J., Perper, J., \& Canobbio, R. (1996b). The impact of adolescent suicide on siblings and parents: A longitudinal follow-up. Suicide and Life-Threatening Behavior, 26, 253-259.

Brent, D.A., Moritz, G., Bridge, J., Perper, J., \& Canobbio, R. (1996c). Long-term impact of exposure to suicide: A three-year controlled follow-up. Journal of the American Academy of Child and Adolescent Psychiatry, 35, 646-653.

Brent, D.A., Oquendo, M., Birmaher, B., Greenhill, L., Kolko, D., Stanley, B., et al. (2002). Familial pathways to early-onset suicide attempt: Risk for suicidal behavior in offspring of mood-disordered suicide attempters. Archives of General Psychiatry, 59, 801807.

Brent, D.A., Oquendo, M., Birmaher, B., Greenhill, L., Kolko, D., Stanley, B., et al. (2003b). Peripubertal suicide attempts in offspring of suicide attempters with siblings concordant for suicidal behavior. American Journal of Psychiatry, 160, 1486-1493.

Brent, D.A., Oquendo, M., Birmaher, B., Greenhill, L., Kolko, D., Stanley, B., et al. (2004b). Familial transmission of mood disorders: Convergence and divergence with transmission of suicidal behavior. Journal of the American Academy of Child and Adolescent Psychiatry, 43, 1259-1266.

Brent, D.A., Perper, J., Moritz, G., Baugher, M., \& Allman, C. (1993c). Suicide in adolescents with no apparent psychopathology. Journal of the American Academy of Child and Adolescent Psychiatry, 32, 494-500.

Brent, D.A., Perper, J.A., Allman, C.J., Moritz, G.M., Wartella, M.E., \& Zelenak, J.P. (1991). The presence and accessibility of firearms in the homes of adolescent suicides. A case-control study. Journal of the American Medical Association, 266, 29892995.

Brent, D.A., Perper, J.A., Goldstein, C.E., Kolko, D.J., Allan, M.J., Allman, C.J., et al. (1988). Risk factors for adolescent suicide. A comparison of adolescent suicide victims with suicidal inpatients. Archives of General Psychiatry, 45, 581-588.

Brent, D.A., Perper, J.A., Moritz, G., Allman, C., Friend, A., Roth, C., et al. (1993). Psychiatric risk factors for adolescent suicide: A case-control study. Journal of the American Academy of Child and Adolescent Psychiatry, 32, 521-529.

Brent, D.A., Perper, J.A., Moritz, G., Baugher, M., Roth, C., Balach, L., et al. (1993e). Stressful life events, psychopathology, and adolescent suicide: A case control study. Suicide and Life-Threatening Behavior, 23, 179-187.

Brent, D.A., Perper, J.A., Moritz, G., Baugher, M., Schweers, J., \& Roth, C. (1993f). Firearms and adolescent suicide. A community case-control study. American Journal of Diseases of Children, 147, 10661071.

Brent, D.A., Perper, J.A., Moritz, G., Liotus, L., Schweers, J., Balach, L., et al. (1994b). Familial risk factors for adolescent suicide: A case-control study. Acta Psychiatrica Scandinavica, 89, 52-58.

Bridge, J.A., Barbe, R.P., \& Brent, D.A. (2005). Datapoints: Recent trends in suicide among U.S. adolescent males, 1992-2001. Psychiatric Services, 56,522 .

Brown, G.K., Ten Have, T., Henriques, G.R., Xie, S.X., Hollander, J.E., \& Beck, A.T. (2005). Cognitive therapy for the prevention of suicide attempts: A randomized controlled trial. Journal of the American Medical Association, 294, 563-570.

Brown, J., Cohen, P., Johnson, J.G., \& Smailes, E.M. (1999). Childhood abuse and neglect: Specificity of effects on adolescent and young adult depression and suicidality. Journal of the American Academy of Child and Adolescent Psychiatry, 38, 1490-1496.

Cantor, C., \& Neulinger, K. (2000). The epidemiology of suicide and attempted suicide among young Australians. Australian and New Zealand Journal of Psychiatry, 34, 370-387.

Cantor, C.H., \& Slater, P.J. (1995). The impact of firearm control legislation on suicide in Queensland: Preliminary findings. Medical Journal of Australia, 162, 583-585. 
Carrington, P.J., \& Moyer, S. (1994). Gun control and suicide in Ontario. American Journal of Psychiatry, 151, 606-608.

Carter, G.L., Clover, K., Whyte, I.M., Dawson, A.H., \& D'Este, C. (2005). Postcards from the EDge project: Randomised controlled trial of an intervention using postcards to reduce repetition of hospital treated deliberate self poisoning. British Medical Journal, 331, 805.

Caspi, A., Sugden, K., Moffitt, T.E., Taylor, A., Craig, I.W., Harrington, H., et al. (2003). Influence of life stress on depression: Moderation by a polymorphism in the 5-HTT gene. Science, 301, 386-389.

Centers for Disease Control and Prevention. (2004). Methods of suicide among persons aged 10-19 years - United States, 1992-2001. MMWR Morbidity and Mortality Weekly Report, 53, 471-474.

Centers for Disease Control and Prevention. (2005). Mortality Query, CDC Wonder, Data and Statistics (http://wonder.cdc.gov/mortSQL.html; accessed 4/ $03 / 2005)$.

Chan, T.Y. (1996). Safety packaging of acetaminophen combination preparations and severity of adult poisoning. Journal of Toxicology - Clinical Toxicology, 34, 747-749.

Cohen-Sandler, R., Berman, A.L., \& King, R.A. (1982). Life stress and symptomatology: Determinants of suicidal behavior in children. Journal of the American Academy of Child Psychiatry, 21, 178-186.

Cummings, P., Grossman, D.C., Rivara, F.P., \& Koepsell, T.D. (1997). State gun safe storage laws and child mortality due to firearms. Journal of the American Medical Association, 278, 1084-1086.

de Chateau, P. (1990). Mortality and aggressiveness in a 30-year follow-up study in child guidance clinics in Stockholm. Acta Psychiatrica Scandinavica, 81, 472476.

de Wilde, E.J., Kienhorst, I.C., Diekstra, R.F., \& Wolters, W.H. (1992). The relationship between adolescent suicidal behavior and life events in childhood and adolescence. American Journal of Psychiatry, 149, 45-51.

de Wilde, E.J., Kienhorst, I.C., Diekstra, R.F., \& Wolters, W.H. (1993). The specificity of psychological characteristics of adolescent suicide attempters. Journal of the American Academy of Child and Adolescent Psychiatry, 32, 51-59.

Demetriades, D., Murray, J., Sinz, B., Myles, D., Chan, L., Sathyaragiswaran, L., et al. (1998). Epidemiology of major trauma and trauma deaths in Los Angeles County. Journal of the American College of Surgeons, 187, 373-383.

Donaldson, D., Spirito, A., \& Esposito-Smythers, C. (2005). Treatment for adolescents following a suicide attempt: Results of a pilot trial. Journal of the American Academy of Child and Adolescent Psychiatry, 44, 113-120.

Drye, R.C., Goulding, R.L., \& Goulding, M.E. (1973). No-suicide decisions: Patient monitoring of suicidal risk. American Journal of Psychiatry, 130, 171-174.

Dubow, E.F., Kausch, D.F., Blum, M.C., Reed, J., \& Bush, E. (1989). Correlates of suicidal ideation and attempts in a community sample of junior high and high school students. Journal of Clinical Child Psychology, 18, 158-166.
Dulcan, M.K., Costello, E.J., Costello, A.J., Edelbrock, C., et al. (1990). The pediatrician as gatekeeper to mental health care for children: Do parents' concerns open the gate? Journal of the American Academy of Child and Adolescent Psychiatry, 29, 453-458.

Eggert, L.L., Thompson, E.A., Herting, J.R., \& Nicholas, L.J. (1995). Reducing suicide potential among highrisk youth: Tests of a school-based prevention program. Suicide and Life-Threatening Behavior, 25, 276-296.

Enns, M.W., Cox, B.J., \& Inayatulla, M. (2003). Personality predictors of outcome for adolescents hospitalized for suicidal ideation. Journal of the American Academy of Child and Adolescent Psychiatry, 42, 720-727.

Evans, E., Hawton, K., \& Rodham, K. (2004). Factors associated with suicidal phenomena in adolescents: A systematic review of population-based studies. Clinical Psychology Review, 24, 957-979.

FDA. (2004). US Food and Drug Administration. Relationship between psychotropic drugs and pediatric suicidality. http:/ /www.fda.gov/ohrms/dockets/ac/04/ briefing/2004-4065b1-10-TAB08-Hammads-Review. pdf. Retrieved January 10, 2005.

Fergusson, D.M., Beautrais, A.L., \& Horwood, L.J. (2003). Vulnerability and resiliency to suicidal behaviours in young people. Psychological Medicine, 33, 61-73.

Fergusson, D.M., Horwood, L.J., \& Beautrais, A.L. (1999). Is sexual orientation related to mental health problems and suicidality in young people? Archives of General Psychiatry, 56, 876-880.

Fergusson, D.M., Horwood, L.J., \& Lynskey, M.T. (1996). Childhood sexual abuse and psychiatric disorder in young adulthood: II. Psychiatric outcomes of childhood sexual abuse. Journal of the American Academy of Child and Adolescent Psychiatry, 35, 1365-1374.

Fergusson, D.M., \& Lynskey, M.T. (1995a). Childhood circumstances, adolescent adjustment, and suicide attempts in a New Zealand birth cohort. Journal of the American Academy of Child and Adolescent Psychiatry, 34, 612-622.

Fergusson, D.M., \& Lynskey, M.T. (1995b). Suicide attempts and suicidal ideation in a birth cohort of 16year-old New Zealanders. Journal of the American Academy of Child and Adolescent Psychiatry, 34, 1308-1317.

Fergusson, D.M., Woodward, L.J., \& Horwood, L.J. (2000). Risk factors and life processes associated with the onset of suicidal behaviour during adolescence and early adulthood. Psychological Medicine, 30, 2339.

Frankenfield, D.L., Keyl, P.M., Gielen, A., Wissow, L.S., Werthamer, L., \& Baker, S.P. (2000). Adolescent patients - healthy or hurting? Missed opportunities to screen for suicide risk in the primary care setting. Archives of Pediatrics and Adolescent Medicine, 154, $162-168$.

Garfinkel, B.D., Froese, A., \& Hood, J. (1982). Suicide attempts in children and adolescents. American Journal of Psychiatry, 139, 1257-1261.

Garofalo, R., Wolf, R.C., Wissow, L.S., Woods, E.R., \& Goodman, E. (1999). Sexual orientation and risk of suicide attempts among a representative sample of 
youth. Archives of Pediatrics and Adolescent Medicine, 153, 487-493.

Garrison, C.Z., Jackson, K.L., Addy, C.L., McKeown, R.E., \& Waller, J.L. (1991). Suicidal behaviors in young adolescents. American Journal of Epidemiology, 133, 1005-1014.

Garrison, C.Z., McKeown, R.E., Valois, R.F., \& Vincent, M.L. (1993). Aggression, substance use, and suicidal behaviors in high school students. American Journal of Public Health, 83, 179-184.

Gartrell, J.W., Jarvis, G.K., \& Derksen, L. (1993). Suicidality among adolescent Alberta Indians. Suicide and Life-Threatening Behavior, 23, 366-373.

Goldsmith, S.K., Pellmar, T.C., Kleinman, A.M., \& Bunney, W.E. (2002). Reducing suicide: A national imperative. Washington, DC: National Academy Press.

Goldstein, T.R., Birmaher, B., Axelson, D., Ryan, N.D., Keller, M., Strober, M.A., et al. (in press). History of suicide attempts in pediatric bipolar disorder: Factors associated with increased risk. Bipolar Disorders.

Goldston, D.B., Daniel, S.S., Reboussin, B.A., Reboussin, D.M., Frazier, P.H., \& Harris, A.E. (2001). Cognitive risk factors and suicide attempts among formerly hospitalized adolescents: A prospective naturalistic study. Journal of the American Academy of Child and Adolescent Psychiatry, 40, 91-99.

Goldston, D.B., Daniel, S.S., Reboussin, D.M., Reboussin, B.A., Frazier, P.H., \& Kelley, A.E. (1999). Suicide attempts among formerly hospitalized adolescents: A prospective naturalistic study of risk during the first 5 years after discharge. Journal of the American Academy of Child and Adolescent Psychiatry, 38, 660-671.

Goldston, D.B., Kovacs, M., Ho, V.Y., Parrone, P.L., \& Stiffler, L. (1994). Suicidal ideation and suicide attempts among youth with insulin-dependent diabetes mellitus. Journal of the American Academy of Child and Adolescent Psychiatry, 33, 240-246.

Gould, M.S. (2001). Suicide and the media. Annals of the New York Academy of Sciences, 932, 200-221; discussion 221-224.

Gould, M.S., Fisher, P., Parides, M., Flory, M., \& Shaffer, D. (1996). Psychosocial risk factors of child and adolescent completed suicide. Archives of General Psychiatry, 53, 1155-1162.

Gould, M.S., Greenberg, T., Velting, D.M., \& Shaffer, D. (2003). Youth suicide risk and preventive interventions: A review of the past 10 years. Journal of the American Academy of Child and Adolescent Psychiatry, 42, 386-405.

Gould, M.S., King, R., Greenwald, S., Fisher, P., Schwab-Stone, M., Kramer, R., et al. (1998). Psychopathology associated with suicidal ideation and attempts among children and adolescents. Journal of the American Academy of Child and Adolescent Psychiatry, 37, 915-923.

Gould, M.S., Marrocco, F.A., Kleinman, M., Thomas, J.G., Mostkoff, K., Cote, J., et al. (2005). Evaluating iatrogenic risk of youth suicide screening programs: A randomized controlled trial. Journal of the American Medical Association, 293, 1635-1643.

Gould, M.S., Petrie, K., Kleinman, M.H., \& Wallenstein, S. (1994). Clustering of attempted suicide: New Zealand national data. International Journal of Epidemiology, 23, 1185-1189.
Gould, M.S., \& Shaffer, D. (1986). The impact of suicide in television movies. Evidence of imitation. New England Journal of Medicine, 315, 690-694.

Gould, M.S., Wallenstein, S., \& Kleinman, M. (1990a). Time-space clustering of teenage suicide. American Journal of Epidemiology, 131, 71-78.

Gould, M.S., Wallenstein, S., Kleinman, M.H., O'Carroll, P., \& Mercy, J. (1990b). Suicide clusters: An examination of age-specific effects. American Journal of Public Health, 80, 211-212.

Granboulan, V., Roudot-Thoraval, F., Lemerle, S., \& Alvin, P. (2001). Predictive factors of post-discharge follow-up care among adolescent suicide attempters. Acta Psychiatrica Scandinavica, 104, 31-36.

Gray, D., Achilles, J., Keller, T., Tate, D., Haggard, L., Rolfs, R., et al. (2002). Utah youth suicide study, phase I: Government agency contact before death. Journal of the American Academy of Child and Adolescent Psychiatry, 41, 427-434.

Greenhill, L., Waslick, B., Parides, M., Fan, B., Shaffer, D., \& Mann, J.J. (1995). Biological studies in suicidal adolescent inpatients. Paper presented at the Scientific Proceedings of the Annual Meeting of the American Academy of Child and Adolescent Psychiatry, New York.

Greenhill, L.L., \& Waslick, B. (1997). Management of suicidal behavior in children and adolescents. Psychiatric Clinics of North America, 20, 641-666.

Groholt, B., Ekeberg, O., Wichstrom, L., \& Haldorsen, T. (1997). Youth suicide in Norway, 1990-1992: A comparison between children and adolescents completing suicide and age- and gender-matched controls. Suicide and Life-Threatening Behavior, 27, 250-263.

Groholt, B., Ekeberg, O., Wichstrom, L., \& Haldorsen, T. (1998). Suicide among children and younger and older adolescents in Norway: A comparative study. Journal of the American Academy of Child and Adolescent Psychiatry, 37, 473-481.

Groholt, B., Ekeberg, O., Wichstrom, L., \& Haldorsen, T. (2000). Young suicide attempters: A comparison between a clinical and an epidemiological sample. Journal of the American Academy of Child and Adolescent Psychiatry, 39, 868-875.

Grossman, D.C., Cummings, P., Koepsell, T.D., Marshall, J., D'Ambrosio, L., Thompson, R.S., et al. (2000). Firearm safety counseling in primary care pediatrics: A randomized, controlled trial. Pediatrics, 106(1 Pt 1), 22-26.

Grossman, D.C., Milligan, B.C., \& Deyo, R.A. (1991). Risk factors for suicide attempts among Navajo adolescents. American Journal of Public Health, 81, 870-874.

Grossman, D.C., Mueller, B.A., Riedy, C., Dowd, M.D., Villaveces, A., Prodzinski, J., et al. (2005). Gun storage practices and risk of youth suicide and unintentional firearm injuries. Journal of the American Medical Association, 293, 707-714.

Grunbaum, J.A., Kann, L., Kinchen, S., Ross, J., Hawkins, J., Lowry, R., et al. (2004). Youth risk behavior surveillance - United States, 2003. MMWR Surveillance Summaries: Morbidity and Mortality Weekly Report Surveillance Summaries/CDC, 53(2), 1-96.

Gunnell, D., Hawton, K., Murray, V., Garnier, R., Bismuth, C., Fagg, J., et al. (1997a). Use of 
paracetamol for suicide and non-fatal poisoning in the UK and France: Are restrictions on availability justified? Journal of Epidemiology and Community Health, 51, 175-179.

Gunnell, D., Murray, V., \& Hawton, K. (2000). Use of paracetamol (acetaminophen) for suicide and nonfatal poisoning: Worldwide patterns of use and misuse. Suicide and Life-Threatening Behavior, 30, 313-326.

Gunnell, D., \& Nowers, M. (1997b). Suicide by jumping. Acta Psychiatrica Scandinavica, 96, 1-6.

Guthrie, E., Kapur, N., Mackway-Jones, K., ChewGraham, C., Moorey, J., Mendel, E., et al. (2001). Randomised controlled trial of brief psychological intervention after deliberate self poisoning. British Medical Journal, 323, 135-138.

Harrington, R., Kerfoot, M., Dyer, E., McNiven, F., Gill, J., Harrington, V., et al. (1998). Randomized trial of a home-based family intervention for children who have deliberately poisoned themselves. Journal of the American Academy of Child and Adolescent Psychiatry, 37, 512-518.

Hau, K.T. (1993). Suicide in Hong Kong 1971-1990: Age trend, sex ratio, and method of suicide. Social Psychiatry and Psychiatric Epidemiology, 28, 23-27.

Hawton, K., \& Catalan, J. (1987). Attempted suicide: A practical guide to its nature and management. New York: Oxford University Press.

Hawton, K., \& Goldacre, M. (1982b). Hospital admissions for adverse effects of medicinal agents (mainly self-poisoning) among adolescents in the Oxford Region. British Journal of Psychiatry, 141, 166-170.

Hawton, K., Townsend, E., Deeks, J., Appleby, L., Gunnell, D., Bennewith, O., et al. (2001). Effects of legislation restricting pack sizes of paracetamol and salicylate on self poisoning in the United Kingdom: Before and after study. British Medical Journal, 322, 1203-1207.

Hawton, K., Ware, C., Mistry, H., Hewitt, J., Kingsbury, S., Roberts, D., et al. (1996). Paracetamol self-poisoning. Characteristics, prevention and harm reduction. British Journal of Psychiatry, 168, 43-48.

Hawton, K., Zahl, D., \& Weatherall, R. (2003). Suicide following deliberate self-harm: Long-term follow-up of patients who presented to a general hospital. British Journal of Psychiatry, 182, 537-542.

Hazell, P., \& Lewin, T. (1993). Friends of adolescent suicide attempters and completers. Journal of the American Academy of Child and Adolescent Psychiatry, 32, 76-81.

Ho, T.P., Leung, P.W., Hung, S.F., Lee, C.C., \& Tang, C.P. (2000). The mental health of the peers of suicide completers and attempters. Journal of Child Psychology and Psychiatry, 41, 301-308.

Huey, S.J., Jr., Henggeler, S.W., Rowland, M.D., Halliday-Boykins, C.A., Cunningham, P.B., Pickrel, S.G., et al. (2004). Multisystemic therapy effects on attempted suicide by youths presenting psychiatric emergencies. Journal of the American Academy of Child and Adolescent Psychiatry, 43, 183-190.

Jaffee, S.R., Moffitt, T.E., Caspi, A., Fombonne, E., Poulton, R., \& Martin, J. (2002). Differences in early childhood risk factors for juvenile-onset and adultonset depression. Archives of General Psychiatry, 59, 215-222.
Ji, J., Kleinman, A., \& Becker, A.E. (2001). Suicide in contemporary China: A review of China's distinctive suicide demographics in their sociocultural context. Harvard Review of Psychiatry, 9, 1-12.

Joe, S., \& Kaplan, M. S. (2002). Firearm-related suicide among young African-American males. Psychiatric Services, 53, 332-334.

Joffe, R.T., Offord, D.R., \& Boyle, M.H. (1988). Ontario Child Health Study: Suicidal behavior in youth age 12-16 years. American Journal of Psychiatry, 145, 1420-1423.

Johnson, B.A., Brent, D.A., Bridge, J., \& Connolly, J. (1998). The familial aggregation of adolescent suicide attempts. Acta Psychiatrica Scandinavica, 97, 18-24.

Johnson, J.G., Cohen, P., Gould, M.S., Kasen, S., Brown, J., \& Brook, J.S. (2002). Childhood adversities, interpersonal difficulties, and risk for suicide attempts during late adolescence and early adulthood. Archives of General Psychiatry, 59, 741-749.

Kalafat, J., \& Elias, M. (1994). An evaluation of a school-based suicide awareness intervention. Suicide and Life-Threatening Behavior, 24, 224-233.

Kashden, J., Fremouw, W.J., Callahan, T.S., \& Franzen, M.D. (1993). Impulsivity in suicidal and nonsuicidal adolescents. Journal of Abnormal Child Psychology, 21, 339-353.

Katz, L.Y., Cox, B.J., Gunasekara, S., \& Miller, A.L. (2004). Feasibility of dialectical behavior therapy for suicidal adolescent inpatients. Journal of the American Academy of Child and Adolescent Psychiatry, 43, 276-282.

Kelleher, M.J., \& Chambers, D. (2003). Cross-cultural aspects of adolescent suicide. In R.A. King \& A. Apter (Eds.), Suicide in children and adolescents (pp. 170197). Cambridge: Cambridge University Press.

Kellermann, A.L., Rivara, F.P., Somes, G., Reay, D.T., Francisco, J., Banton, J.G., et al. (1992). Suicide in the home in relation to gun ownership. New England Journal of Medicine, 327, 467-472.

Kelly, K.T., \& Knudson, M.P. (2000). Are no-suicide contracts effective in preventing suicide in suicidal patients seen by primary care physicians? Archives of Family Medicine, 9, 1119-1121.

Kerfoot, M., Dyer, E., Harrington, V., Woodham, A., \& Harrington, R. (1996). Correlates and short-term course of self-poisoning in adolescents. British Journal of Psychiatry, 168, 38-42.

Kienhorst, I.C., De Wilde, E.J., Diekstra, R.F., \& Wolters, W.H. (1995). Adolescents' image of their suicide attempt. Journal of the American Academy of Child and Adolescent Psychiatry, 34, 623-628.

Killias, M. (1993). International correlations between gun ownership and rates of homicide and suicide. Canadian Medical Association Journal, 148, 17211725.

King, C.A., Kramer, A., Preuss, L., Kerr, D.C., Weisse, L., \& Venkataraman, S. (in press). Youth-nominated support team for suicidal adolescents (version 1): A randomized controlled trial. Journal of Consulting and Clinical Psychology.

King, R.A., Schwab-Stone, M., Flisher, A.J., Greenwald, S., Kramer, R.A., Goodman, S.H., et al. (2001). Psychosocial and risk behavior correlates of youth suicide attempts and suicidal ideation. Journal of the 
American Academy of Child and Adolescent Psychiatry, 40, 837-846.

Kingsbury, S., Hawton, K., Steinhardt, K., \& James, A. (1999). Do adolescents who take overdoses have specific psychological characteristics? A comparative study with psychiatric and community controls. Journal of the American Academy of Child and Adolescent Psychiatry, 38, 1125-1131.

Kingsbury, S.J. (1993). Clinical components of suicidal intent in adolescent overdose. Journal of the American Academy of Child and Adolescent Psychiatry, 32, 518-520.

Kosky, R., Silburn, S., \& Zubrick, S.R. (1990). Are children and adolescents who have suicidal thoughts different from those who attempt suicide? Journal of Nervous and Mental Disease, 178, 38-43.

Kotila, L., \& Lonnqvist, J. (1989). Suicide and violent death among adolescent suicide attempters. Acta Psychiatrica Scandinavica, 79, 453-459.

Kruesi, M.J., Grossman, J., Pennington, J.M., Woodward, P.J., Duda, D., \& Hirsch, J.G. (1999). Suicide and violence prevention: Parent education in the emergency department. Journal of the American Academy of Child and Adolescent Psychiatry, 38, 250-255.

Kruesi, M.J., Hibbs, E.D., Zahn, T.P., Keysor, C.S., Hamburger, S.D., Bartko, J.J., et al. (1992). A 2-year prospective follow-up study of children and adolescents with disruptive behavior disorders. Prediction by cerebrospinal fluid 5-hydroxyindoleacetic acid, homovanillic acid, and autonomic measures? Archives of General Psychiatry, 49, 429435.

Kruesi, M.J., Rapoport, J.L., Hamburger, S., Hibbs, E., Potter, W.Z., Lenane, M., et al. (1990). Cerebrospinal fluid monoamine metabolites, aggression, and impulsivity in disruptive behavior disorders of children and adolescents. Archives of General Psychiatry, 47, 419426.

Krug, E.G., Dahlberg, L.L., \& Powell, K.E. (1996). Childhood homicide, suicide, and firearm deaths: An international comparison. World Health Statistics Quarterly - Rapport Trimestriel de Statistiques Sanitaires Mondiales, 49, 230-235.

Kuperman, S., Black, D.W., \& Burns, T.L. (1988). Excess suicide among formerly hospitalized child psychiatry patients. Journal of Clinical Psychiatry, 49, 88-93.

Lewinsohn, P.M., Gotlib, I.H., \& Seeley, J.R. (1997). Depression-related psychosocial variables: Are they specific to depression in adolescents? Journal of Abnormal Psychology, 106, 365-375.

Lewinsohn, P.M., Klein, D.N., \& Seeley, J.R. (1995). Bipolar disorders in a community sample of older adolescents: Prevalence, phenomenology, comorbidity, and course. Journal of the American Academy of Child and Adolescent Psychiatry, 34, 454-463.

Lewinsohn, P.M., Rohde, P., \& Seeley, J.R. (1994). Psychosocial risk factors for future adolescent suicide attempts. Journal of Consulting and Clinical Psychology, 62, 297-305.

Lewinsohn, P.M., Rohde, P., \& Seeley, J.R. (1996). Adolescent suicidal ideation and attempts: Prevalence, risk factors, and clinical implications. Clinical Psychology Science and Practice, 3, 25-36.
Lieb, R., Bronisch, T., Hofler, M., Schreier, A., \& Wittchen, H.U. (2005). Maternal suicidality and risk of suicidality in offspring: Findings from a community study. American Journal of Psychiatry, 162, 16651671.

Linehan, M.M., Armstrong, H.E., Suarez, A., Allmon, D., \& Heard, H.L. (1991). Cognitive-behavioral treatment of chronically parasuicidal borderline patients. Archives of General Psychiatry, 48, 1060-1064.

Loftin, C., McDowall, D., Wiersema, B., \& Cottey, T.J. (1991). Effects of restrictive licensing of handguns on homicide and suicide in the District of Columbia. New England Journal of Medicine, 325, 1615-1620.

Ludwig, J., \& Marcotte, D.E. (2005). Anti-depressants, suicide, and drug regulation. Journal of Policy Analysis and Management, 24, 249-272.

Luoma, J.B., Martin, C.E., \& Pearson, J.L. (2002). Contact with mental health and primary care providers before suicide: A review of the evidence. American Journal of Psychiatry, 159, 909-916.

Malone, K.M., Corbitt, E.M., Li, S., \& Mann, J.J. (1996). Prolactin response to fenfluramine and suicide attempt lethality in major depression. British Journal of Psychiatry, 168, 324-329.

Mann, J.J. (1998). The neurobiology of suicide. Nature Medicine, 4, 25-30.

Mann, J.J. (2003). Neurobiology of suicidal behaviour. Nature Reviews Neuroscience, 4, 819-828.

Mann, J.J., Waternaux, C., Haas, G.L., \& Malone, K.M. (1999). Toward a clinical model of suicidal behavior in psychiatric patients. American Journal of Psychiatry, 156, 181-189.

March, J., Silva, S., Petrycki, S., Curry, J., Wells, K., Fairbank, J., et al. (2004). Fluoxetine, cognitivebehavioral therapy, and their combination for adolescents with depression: Treatment for Adolescents with Depression Study (TADS) randomized controlled trial. Journal of the American Medical Association, 292, 807-820.

Marttunen, M.J., Aro, H.M., Henriksson, M.M., \& Lonnqvist, J.K. (1991). Mental disorders in adolescent suicide. DSM-III-R axes I and II diagnoses in suicides among 13- to 19-year-olds in Finland. Archives of General Psychiatry, 48, 834-839.

Marttunen, M.J., Aro, H.M., Henriksson, M.M., \& Lonnqvist, J.K. (1994b). Psychosocial stressors more common in adolescent suicides with alcohol abuse compared with depressive adolescent suicides. Journal of the American Academy of Child and Adolescent Psychiatry, 33, 490-497.

Marttunen, M.J., Aro, H.M., \& Lonnqvist, J.K. (1992). Adolescent suicide: Endpoint of long-term difficulties. Journal of the American Academy of Child and Adolescent Psychiatry, 31, 649-654.

Marttunen, M.J., Henriksson, M.M., Isometsa, E.T., Heikkinen, M.E., Aro, H.M., \& Lonnqvist, J.K. (1998). Completed suicide among adolescents with no diagnosable psychiatric disorder. Adolescence, 33, 669681.

Mazza, J.J. (2000). The relationship between posttraumatic stress symptomatology and suicidal behavior in school-based adolescents. Suicide and Life-Threatening Behavior, 30, 91-103.

McManus, B.L., Kruesi, M.J., Dontes, A.E., Defazio, C.R., Piotrowski, J.T., \& Woodward, P.J. (1997). Child 
and adolescent suicide attempts: An opportunity for emergency departments to provide injury prevention education. American Journal of Emergency Medicine, 15, 357-360.

Miller, A.L., Rathus, J.H., Linehan, M.M., Wetzler, S., \& Leigh, E. (1997). Dialectical behavior therapy adapted for suicidal adolescents. Journal of Practical Psychiatry and Behavioral Health, 3, 78-86.

Molnar, B.E., Berkman, L.F., \& Buka, S.L. (2001). Psychopathology, childhood sexual abuse and other childhood adversities: Relative links to subsequent suicidal behaviour in the US. Psychological Medicine, 31, 965-977.

O’Carroll, P.W., Berman, A.L., Maris, R.W., Moscicki, E.K., Tanney, B.L., \& Silverman, M.M. (1996). Beyond the Tower of Babel: A nomenclature for suicidology. Suicide and Life-Threatening Behavior, 26, 237-252.

Olfson, M., Shaffer, D., Marcus, S.C., \& Greenberg, T. (2003). Relationship between antidepressant medication treatment and suicide in adolescents. Archives of General Psychiatry, 60, 978-982.

Oquendo, M., Brent, D.A., Birmaher, B., Greenhill, L., Kolko, D., Stanley, B., et al. (2005). Posttraumatic stress disorder comorbid with major depression: Factors mediating the association with suicidal behavior. American Journal of Psychiatry, 162, 560566.

Otto, U. (1972). Suicidal acts by children and adolescents. A follow-up study. Acta Psychiatrica Scandinavica, Supplementum, 233, 7-123.

Overholser, J.C., Adams, D.M., Lehnert, K.L., \& Brinkman, D.C. (1995). Self-esteem deficits and suicidal tendencies among adolescents. Journal of the American Academy of Child and Adolescent Psychiatry, 34, 919-928.

Pandey, G.N. (1997). Altered serotonin function in suicide. Evidence from platelet and neuroendocrine studies. Annals of the New York Academy of Sciences, 836, 182-200.

Pandey, G.N., Dwivedi, Y., Rizavi, H.S., Ren, X., \& Conley, R.R. (2004). Decreased catalytic activity and expression of protein kinase $\mathrm{C}$ isozymes in teenage suicide victims: A postmortem brain study. Archives of General Psychiatry, 61, 685-693.

Pandey, G.N., Dwivedi, Y., Rizavi, H.S., Ren, X., Pandey, S.C., Pesold, C., et al. (2002). Higher expression of serotonin 5-HT(2A) receptors in the postmortem brains of teenage suicide victims. American Journal of Psychiatry, 159, 419-429.

Pelkonen, M., \& Marttunen, M. (2003). Child and adolescent suicide: Epidemiology, risk factors, and approaches to prevention. Paediatric Drugs, 5, 243265.

Pfeffer, C.R., Hurt, S.W., Kakuma, T., Peskin, J.R., Siefker, C.A., \& Nagabhairava, S. (1994a). Suicidal children grow up: Suicidal episodes and effects of treatment during follow-up. Journal of the American Academy of Child and Adolescent Psychiatry, 33, 225-230.

Pfeffer, C.R., Normandin, L., \& Kakuma, T. (1994b). Suicidal children grow up: Suicidal behavior and psychiatric disorders among relatives. Journal of the American Academy of Child and Adolescent Psychiatry, 33, 1087-1097.
Pfeffer, C.R., Plutchik, R., \& Mizruchi, M.S. (1983). Suicidal and assaultive behavior in children: Classification, measurement, and interrelations. American Journal of Psychiatry, 140, 154-157.

Phillips, D.P., \& Carstensen, L.L. (1986). Clustering of teenage suicides after television news stories about suicide. New England Journal of Medicine, 315, 685689.

Phillips, M.R., Liu, H., \& Zhang, Y. (1999). Suicide and social change in China. Culture, Medicine and Psychiatry, 23, 25-50.

Pilowsky, D.J., Wu, L.T., \& Anthony, J.C. (1999). Panic attacks and suicide attempts in mid-adolescence. American Journal of Psychiatry, 156, 1545-1549.

Pine, D.S., Coplan, J.D., Wasserman, G.A., Miller, L.S., Fried, J.E., Davies, M., et al. (1997). Neuroendocrine response to fenfluramine challenge in boys. Associations with aggressive behavior and adverse rearing. Archives of General Psychiatry, 54, 839-846.

Pompili, M., Mancinelli, I., Girardi, P., Ruberto, A., \& Tatarelli, R. (2004). Suicide in anorexia nervosa: A meta-analysis. International Journal of Eating Disorders, 36, 99-103.

Prigerson, H.G., Bridge, J., Maciejewski, P.K., Beery, L.C., Rosenheck, R.A., Jacobs, S.C., et al. (1999). Influence of traumatic grief on suicidal ideation among young adults. American Journal of Psychiatry, 156, 1994-1995.

Reid, W.H. (1998). Promises, promises: Don't rely on patients' no-suicide/no-violence 'contracts'. Journal of Practical Psychiatry and Behavioral Health, 4, 316318.

Reinherz, H.Z., Giaconia, R.M., Silverman, A.B., Friedman, A., Pakiz, B., Frost, A.K., et al. (1995). Early psychosocial risks for adolescent suicidal ideation and attempts. Journal of the American Academy of Child and Adolescent Psychiatry, 34, 599-611.

Remafedi, G., Farrow, J.A., \& Deisher, R.W. (1991). Risk factors for attempted suicide in gay and bisexual youth. Pediatrics, 87, 869-875.

Remafedi, G., French, S., Story, M., Resnick, M.D., \& Blum, R. (1998). The relationship between suicide risk and sexual orientation: Results of a populationbased study. American Journal of Public Health, 88, 57-60.

Renaud, J., Brent, D.A., Birmaher, B., Chiappetta, L., \& Bridge, J. (1999). Suicide in adolescents with disruptive disorders. Journal of the American Academy of Child and Adolescent Psychiatry, 38, 846-851.

Resnick, M.D., Bearman, P.S., Blum, R.W., Bauman, K.E., Harris, K.M., Jones, J., et al. (1997). Protecting adolescents from harm. Findings from the National Longitudinal Study on Adolescent Health. Journal of the American Medical Association, 278, 823-832.

Rey Gex, C., Narring, F., Ferron, C., \& Michaud, P.A. (1998). Suicide attempts among adolescents in Switzerland: Prevalence, associated factors and comorbidity. Acta Psychiatrica Scandinavica, 98, 28-33.

Rotheram-Borus, M.J., \& Bradley, J. (1990). Evaluation of suicide risk. In M.J. Rotheram-Borus, J. Bradley, \& N. Obolensky (Eds.), Planning to live: Evaluating and treating suicidal teens in community settings ( $\mathrm{pp}$. 109-136). Oklahoma: National Resource Center for Youth Services. 
Rotheram-Borus, M.J., \& Bradley, J. (1991). Triage model for suicidal runaways. American Journal of Orthopsychiatry, 61, 122-127.

Rotheram-Borus, M. J., Piacentini, J., Cantwell, C., Belin, T.R., \& Song, J. (2000). The 18-month impact of an emergency room intervention for adolescent female suicide attempters. Journal of Consulting and Clinical Psychology, 68, 1081-1093.

Rotheram-Borus, M.J., Piacentini, J., Miller, S., Graae, F., Dunne, E., \& Cantwell, C. (1996a). Toward improving treatment adherence among adolescent suicide attempters. Clinical Child Psychology and Psychiatry, 1, 99-108.

Rotheram-Borus, M.J., Piacentini, J., Van Rossem, R., Graae, F., Cantwell, C., Castro-Blanco, D., et al. (1996b). Enhancing treatment adherence with a specialized emergency room program for adolescent suicide attempters. Journal of the American Academy of Child and Adolescent Psychiatry, 35, 654-663.

Roy, A. (2002). Family history of suicide and neuroticism: A preliminary study. Psychiatry Research, 110, 87-90.

Russell, S.T., \& Joyner, K. (2001). Adolescent sexual orientation and suicide risk: Evidence from a national study. American Journal of Public Health, 91, 12761281.

Ryan, N.D., Puig-Antich, J., Ambrosini, P., Rabinovich, H., Robinson, D., Nelson, B., et al. (1987). The clinical picture of major depression in children and adolescents. Archives of General Psychiatry, 44, 854-861.

Schmidtke, A., \& Schaller, S. (2000). The role of mass media in suicide prevention. In K. Hawton \& K. van Heeringen (Eds.), The international handbook of suicide and attempted suicide (pp. 675-698). New York: Wiley.

Shaffer, D. (1974). Suicide in childhood and early adolescence. Journal of Child Psychology and Psychiatry, 15, 275-291.

Shaffer, D., Fisher, P., Hicks, R.H., Parides, M., \& Gould, M. (1995). Sexual orientation in adolescents who commit suicide. Suicide and Life-Threatening Behavior, 25 Suppl., 64-71.

Shaffer, D., Garland, A., Vieland, V., Underwood, M., \& Busner, C. (1991). The impact of curriculum-based suicide prevention programs for teenagers. Journal of the American Academy of Child and Adolescent Psychiatry, 30, 588-596.

Shaffer, D., \& Gould, M. (2000). Suicide prevention in schools. In K. Hawton \& K. van Heeringen (Eds.), The international handbook of suicide and attempted suicide. Chichester: Wiley.

Shaffer, D., Gould, M., \& Hicks, R. C. (1994). Worsening suicide rate in black teenagers. American Journal of Psychiatry, 151, 1810-1812.

Shaffer, D., Gould, M.S., Fisher, P., Trautman, P., Moreau, D., Kleinman, M., et al. (1996). Psychiatric diagnosis in child and adolescent suicide. Archives of General Psychiatry, 53, 339-348.

Shaffer, D., \& Pfeffer, C. (2001). Practice parameter for the assessment and treatment of children and adolescents with suicidal behavior. American Academy of Child and Adolescent Psychiatry. Journal of the American Academy of Child and Adolescent Psychiatry, $40(7$ Suppl.), 24S-51S.
Shaffer, D., Scott, M., Wilcox, H., Maslow, C., Hicks, R., Lucas, C. P., et al. (2004). The Columbia Suicide Screen: Validity and reliability of a screen for youth suicide and depression. Journal of the American Academy of Child and Adolescent Psychiatry, 43, 71-79.

Shaffer, D., Vieland, V., Garland, A., Rojas, M., Underwood, M., \& Busner, C. (1990). Adolescent suicide attempters. Response to suicide-prevention programs. Journal of the American Medical Association, 264, 3151-3155.

Shafii, M., Carrigan, S., Whittinghill, J.R., \& Derrick, A. (1985). Psychological autopsy of completed suicide in children and adolescents. American Journal of Psychiatry, 142, 1061-1064.

Shafii, M., Steltz-Lenarsky, J., Derrick, A.M., Beckner, C., \& Whittinghill, J.R. (1988). Comorbidity of mental disorders in the post-mortem diagnosis of completed suicide in children and adolescents. Journal of Affective Disorders, 15, 227-233.

Shah, S., Hoffman, R.E., Wake, L., \& Marine, W.M. (2000). Adolescent suicide and household access to firearms in Colorado: Results of a case-control study. Journal of Adolescent Health, 26, 157-163.

Simpson, M.A. (1975). The phenomenology of selfmutilation in a general hospital setting. Canadian Psychiatric Association Journal, 20, 429-434.

Slap, G.B., Vorters, D.F., Chaudhuri, S., \& Centor, R.M. (1989). Risk factors for attempted suicide during adolescence. Pediatrics, 84, 762-772.

Sloan, J.H., Rivara, F.P., Reay, D.T., Ferris, J.A., \& Kellermann, A.L. (1990). Firearm regulations and rates of suicide. A comparison of two metropolitan areas. New England Journal of Medicine, 322, 369-373.

Spirito, A., Overholser, J., Ashworth, S., Morgan, J., \& Benedict-Drew, C. (1988). Evaluation of a suicide awareness curriculum for high school students. Journal of the American Academy of Child and Adolescent Psychiatry, 27, 705-711.

Spirito, A., Overholser, J., \& Hart, K. (1991). Cognitive characteristics of adolescent suicide attempters. Journal of the American Academy of Child and Adolescent Psychiatry, 30, 604-608.

Stack, S. (2000). Media impacts on suicide: A quantitative review of 293 findings. Social Science Quarterly, 81, 956-971.

Stack, S. (2003). Media coverage as a risk factor in suicide. Journal of Epidemiology and Community Health, 57, 238-240.

Stack, S. (2005). Suicide in the media: A quantitative review of studies based on nonfictional stories. Suicide and Life-Threatening Behavior, 35, 121-133.

Stanford, E.J., Goetz, R.R., \& Bloom, J.D. (1994). The No Harm Contract in the emergency assessment of suicidal risk. Journal of Clinical Psychiatry, 55, 344348.

Taiminen, T.J., Kallio-Soukainen, K., Nokso-Koivisto, H., Kaljonen, A., \& Kelenius, H. (1998). Contagion of deliberate self-harm among adolescent inpatients. Journal of the American Academy of Child and Adolescent Psychiatry, 37, 211-217.

Taylor, E.A., \& Stansfeld, S.A. (1984). Children who poison themselves. I. A clinical comparison with psychiatric controls. British Journal of Psychiatry, 145, 127-132. 
Tousignant, M., Bastien, M.F., \& Hamel, S. (1993). Suicidal attempts and ideations among adolescents and young adults: The contribution of the father's and mother's care and of parental separation. Social Psychiatry and Psychiatric Epidemiology, 28, 256261.

Turvill, J.L., Burroughs, A.K., \& Moore, K.P. (2000). Change in occurrence of paracetamol overdose in UK after introduction of blister packs. Lancet, 355, 20482049.

Vieland, V., Whittle, B., Garland, A., Hicks, R., \& Shaffer, D. (1991). The impact of curriculum-based suicide prevention programs for teenagers: An 18month follow-up. Journal of the American Academy of Child and Adolescent Psychiatry, 30, 811-815.

Wagner, B.M., Cole, R.E., \& Schwartzman, P. (1995). Psychosocial correlates of suicide attempts among junior and senior high school youth. Suicide and LifeThreatening Behavior, 25, 358-372.

Wallace, J.D., Calhoun, A.D., Powell, K.E., O’Neil, J., \& James, S.P. (1996). Homicide and suicide among Native Americans, 1979-1992. Atlanta: Centers for Disease Control and Prevention, National Center for Injury Prevention and Control. Violence Surveillance Series, No. 2.

Webster, D.W., Vernick, J.S., Zeoli, A.M., \& Manganello, J.A. (2004). Association between youth-focused firearm laws and youth suicides. Journal of the American Medical Association, 292, 594-601.

Weissman, M.M., Wolk, S., Goldstein, R.B., Moreau, D., Adams, P., Greenwald, S., et al. (1999). Depressed adolescents grown up. Journal of the American Medical Association, 281, 1707-1713.

Welch, S.S. (2001). A review of the literature on the epidemiology of parasuicide in the general population. Psychiatric Services, 52, 368-375.
Wiebe, D.J. (2003). Homicide and suicide risks associated with firearms in the home: A national casecontrol study. Annals of Emergency Medicine, 41, 771-782.

Wislar, J.S., Grossman, J., Krusei, M.J.P., Fendrich, M., Franke, C., \& Ignatowicz, N. (1998). Youth suicide-related visits in an emergency department serving rural counties: Implications for means restriction. Archives of Suicide Research, 4, 75-87.

Wood, A., Trainor, G., Rothwell, J., Moore, A., \& Harrington, R. (2001). Randomized trial of group therapy for repeated deliberate self-harm in adolescents. Journal of the American Academy of Child and Adolescent Psychiatry, 40, 1246-1253.

World Health Organization. (2002). Suicide rates and absolute numbers of suicide by country (2002). Available online: http://www.who.int/mental_health/prevention/suicide/(accessed April 7, 2005).

Wunderlich, U., Bronisch, T., \& Wittchen, H.U. (1998). Comorbidity patterns in adolescents and young adults with suicide attempts. European Archives of Psychiatry and Clinical Neuroscience, 248, 87-95.

Yuen, N., Andrade, N., Nahulu, L., Makini, G., McDermott, J.F., Danko, G., et al. (1996). The rate and characteristics of suicide attempters in the native Hawaiian adolescent population. Suicide and LifeThreatening Behavior, 26, 27-36.

Zalsman, G., Frisch, A., Bromberg, M., Gelernter, J., Michaelovsky, E., Campino, A., et al. (2001). Familybased association study of serotonin transporter promoter in suicidal adolescents: No association with suicidality but possible role in violence traits. American Journal of Medical Genetics, 105, 239-245.

Manuscript accepted 7 December 2005 